\title{
Cambios en las pautas de localización de las bodegas del entorno de la ciudad de Borja (Zaragoza)
}

\author{
Changes in the location guidelines of the wineries \\ around the city of Borja (Zaragoza)
}

\author{
Samuel Esteban Rodríguez ${ }^{1}$ (i) \\ Julio Fernández Portela ${ }^{2 *}$ (])
}

\section{Resumen}

Las transformaciones en el sector de la vid y el vino han supuesto cambios importantes en los viñedos y en las bodegas de las comarcas vitivinícolas. Estos espacios se han centrado en la elaboración de vinos de calidad bajo alguna figura de protección y que están destinados a mercados cada vez más numerosos, diversos y exigentes. El objetivo de este trabajo consiste en analizar las pautas de localización de las bodegas en el municipio zaragozano de Borja, desde las bodegas rupestres hasta las nuevas bodegas industriales. Para ello se ha elaborado cartografía en la que se reflejan diversas variables que permitan explicar las nuevas pautas de localización, así como la realización de entrevistas a diversos agentes implicados en el sector. Los resultados reflejan cambios significativos en la localización espacial de las bodegas y en su estructura, las cuales abandonan las laderas de los cerros para instalarse en las proximidades de los ejes de comunicación, en las zonas bajas del municipio. Esto es debido a la existencia de mejores comunicaciones, pero también por los cambios en el sistema productivo y de gestión. De forma adicional, recientemente, se está viendo una nueva lógica en la ubicación de las bodegas, en especial de aquellas que elaboran vinos más exclusivos, con emplazamientos que priman el valor ambiental y paisajístico frente al funcional.

Palabras clave: Sector vitivinícola; DOP Borja; bodegas rupestres; bodegas industriales; bodegas de corte elitista; nuevos emplazamientos; sistema productivo.

\begin{abstract}
The transformations in the wine sector have led to important changes in the vineyards and wineries of the wine regions. These spaces have focused on the production of quality wines (under some form of protected designation of origin) and that are destined for increasingly numerous, diverse, and demanding markets. The objective of this work is to analyse the location guidelines of wineries in the Zaragoza municipality of Borja (from cave wineries to new industrial wineries). Maps have been drawn showing the various variables that explain the new location guidelines, and interviews have been conducted with various agents involved in the sector. The results reflect significant changes in the spatial location of wineries and in their structure, many of which have left the hills to settle near the communication centres in the lower areas of the municipality. Production and management systems have also changed. However,

1 Grupo de Estudios de Ordenación del Territorio (GEOT). Departamento de Geografía y Ordenación del Territorio - Universidad de Zaragoza, España. sestebanr@unizar.es

2 Grupo de Investigación VITISUNED. Departamento de Geografía - Universidad Nacional de Educación a Distancia (UNED), España jfportela@geo.uned.es. *Autor para correspondencia
\end{abstract}


recently, a new logic is being seen in the location of wineries, especially those that make more exclusive wines, with locations that prioritise environmental and landscape values over functional value.

Keywords: Wine sector; DOP Borja; troglodyte wineries; industrial wineries; elitist-style wineries; new locations; productive system.

\section{Introducción}

A lo largo de la historia la actividad vitivinícola ha configurado el paisaje en las áreas productoras de vino, tanto en lo que respecta al viñedo como a las bodegas. La diversidad en los sistemas de plantación (vaso, espaldera, emparrado...), en los marcos de plantación, en las variedades de uva, en el tipo de suelo o en su ubicación (bancales, laderas, llanuras, etc.) ha construido una amplia diversidad paisajística de la geografía de la vid en toda España, tanto en viñedos peninsulares como insulares, dando lugar a paisajes tan contrastados como los volcánicos de la Geria en Lanzarote, los abancalados de la Ribeira Sacra y las Arribes del Duero, o los viñedos en llanuras como los de La Mancha, la Ribera del Duero o los del Campo de Borja.

Esta diversidad paisajística se amplía si se tienen en cuenta otros espacios vitivinícolas en el mundo. La vid y el vino han conseguido configurar espacios con unas características específicas que otorgan identidad propia al territorio, haciendo que cada espacio sea único (Rocchi y Gabbai, 2013). Ejemplo de ello es la región vitícola del Alto Duero en Portugal donde el medio natural, la singularidad del terruño, las tradiciones agrícolas y la propia historia, han permitido su declaración como Patrimonio de la Humanidad por la UNESCO en 2001 (Macedo, 2011).

Las complejas relaciones entre las actividades humanas y los accidentes geográficos dan lugar a una variedad contrastada de paisajes del viñedo, como sucede en Italia, con vides desde los abruptos bancales en la Liguria hasta las extensas planicies con ligeras ondulaciones en Sicilia (Amato y Valleta, 2017).

Otro aspecto a mencionar, es el papel que adquiere el enoturismo a la hora de la conformación de los paisajes del vino como ha sucedido en la provincia de Mendoza (Argentina), donde el desarrollo de esta tipología turística y, en este caso, de carácter más acomodado, da lugar al desarrollo de enclaves que requieren unas características estéticas determinadas (Pastor, Torres y Marinsalda Pastor, 2020), como por ejemplo la construcción de bodegas con hoteles de diseños a cargo de arquitectos vanguardistas en la enoarquitectura. En definitiva, estos son algunos ejemplos que reflejan la diversidad de factores que influyen en la conformación del paisaje vitivinícola, donde las bodegas, y su localización, han jugado, y lo siguen haciendo en la actualidad, un papel fundamental a lo largo de la historia.

Las bodegas tradicionales constituyen un elemento esencial en la arquitectura popular de este tipo de paisajes. Además de su papel socio-económico, otorgan valores identitarios al territorio por las peculiaridades que presenta su construcción. Principalmente se distinguen dos tipos: el primero se corresponde con las ubicadas en las casas, habitualmente en el subsuelo. En el segundo tipo se encuentran las bodegas construidas en el exterior. Estas se erigían aprovechando las características orográficas del terreno: desniveles y laderas de los cerros, cuestas y tesos donde predominan materiales blandos como calizas, margas, yesos o arcillas. Estas últimas van a incidir en la conformación del paisaje vitivinícola pues van a ser visibles. Se caracterizan por una tipología arquitectónica muy concreta, aunque presentan ciertos matices entre comarcas (González Hinojo, 1995; Cañas Guerrero, Fuentes Pardo y Martín Ocaña, 2006; Martín Martín, 2016; Jové Sandoval, 2018).

Estas bodegas se agrupan formando barrios, con sus propias calles, construidos en terrenos que podían pertenecer al Concejo o a los Ayuntamientos. La mayoría de estos barrios de bodegas se encuentran anexos a la trama urbana, en ocasiones alejadas del mismo y, también, en algunos casos, debido a la expansión del municipio, han quedado inmersos dentro de la misma conviviendo en la actualidad con las casas (Palacios García, 2014).

En el caso de Borja, las antiguas bodegas ubicadas en dependencias de monasterios o bajo casas, ocuparon nuevos espacios en el siglo XIX. Su expansión se llevó a cabo en forma de bodegas excavadas en la ladera, y en el año 1843 se registra la primera solicitud para construir una bodega en el monte (Chueca Yus, 2004).

En el último tercio del siglo XIX el número de bodegas excavadas en los cerros aumentó a causa de la crisis de la filoxera en Francia. Esta crisis en el país galo repercutió en el sector provocando un incremento de la superficie de vides, de la producción de vino y de la expansión de las bodegas tradicionales. Históricamente, 
en las características técnicas de las explotaciones dominaba la pequeña y fragmentada explotación. Los vinos que se elaboraban en las bodegas tradicionales estaban destinados a un mercado más reducido, menos exigente y cercano, especialmente local y comarcal, aunque en algunos casos, también nacional. Tuvieron que adaptarse a la nueva coyuntura económica. A esta situación, hay que sumar el hecho de que en Francia los vinos se pagaban a un precio más alto, un factor que repercutió en la expansión del sector (Chueca Yus, 2004).

Posteriormente, a lo largo del siglo XX y, especialmente, a partir de los años 50, aparecieron nuevos tipos de bodega que reemplazaron, paulatinamente, a las antiguas bodegas ubicadas en cerro (Huetz de Lemps, 1967a; 1967b). La industrialización desarrolló un modelo basado en grandes instalaciones, que permitían el abastecimiento de los incipientes mercados urbanos (Sánchez Hernández, Aparicio Amador y Alonso Santos, 2010). Sin embargo, este cambio en el modelo de producción ha provocado un grave problema en el mantenimiento y conservación de las viejas bodegas, muchas de las cuales, están abocadas a la desaparición si no se ponen en marcha políticas que contribuyan a conservar este patrimonio etnográfico (Fernández Portela y García Velasco, 2014).

Además de la repercusión de estos cambios en las bodegas, los viñedos también se vieron afectados. Tuvieron lugar importantes transformaciones en las explotaciones. Entre los cambios más significativos destacan los abandonos y arranques de las viñas viejas para ser replantadas, en algunas ocasiones, por nuevas variedades, con marcos de plantación más intensivos. Con ello se perseguía incrementar la producción de uva por hectárea que permitiera hacer frente a las nuevas demandas de los consumidores, hacer que los cultivos fueran más rentables, luchar contra la fuerte competencia del sector con precios más competitivos, así como a los nuevos gustos de los consumidores que demandan vinos de diversas variedades de uva, con diferentes aromas y colores y nuevas sensaciones en los paladares.

Actualmente, la industria vitivinícola se ha enfocado hacia la elaboración de vinos de calidad (Loscertales, Escalona y Climent, 2011; Steakley y Steakley, 2020), amparados en alguna figura de protección, en especial las Denominaciones de Origen Protegidas (DOP), que se han expandido por toda España, 96 en total $^{3}$, que abarcan una parte significativa de las tradicionales comarcas vitivinícolas. Para ello ha sido necesario la puesta en práctica de un sistema de innovación vitivinícola que integra a diversos agentes, públicos y privados, como son los Consejos Reguladores, las estaciones enológicas, las universidades, los Servicios de Investigación y Tecnología Agraria de las Comunidades Autónomas, las escuelas de capacitación agraria, los laboratorios, los viveros de vides, etc., que han modificado el tradicional modelo vitivinícola, así como el entramado socioeconómico y cultural (Alonso Santos, 2003; Sánchez Hernández, 2003).

El desarrollo de la nueva cultura del vino (Bujan, 2003) supone un cambio dentro del sector, pues el vino deja de ser demandado eminentemente como producto alimenticio y ganan protagonismo otras convenciones de calidad (Alonso Santos, Aparicio Amador y Sánchez Hernández, 2003; Martínez-Carrasco, Brugarolas y Martínez-Poveda, 2005; Ruiz Budría et al., 2013). Este nuevo paradigma dirige al sector hacia una producción orientada a mercados personalizados que demandan productos de alta calidad. En España incluso se ha llegado a reconocer legalmente una figura de protección específica, el Pago Vitícola, que se asocia de forma directa a este modelo de producción (Esteban Rodríguez, 2017). Este se ha expandido por la mayor parte de las denominaciones de origen españolas, en ocasiones a cargo de capital local, pero en otros casos con capital procedente de empresas que se encuentran presentes en otras comarcas vitivinícolas españolas y extranjeras (Escalona Orcao, Loscertales Palomar y Climent López, 2013).

Desde un punto de vista territorial, la conexión entre paisaje, bodegas y vino de calidad contribuye a promover el desarrollo en los territorios rurales. La construcción de nuevas bodegas elaboradoras de vinos de calidad tienen en cuenta los instrumentos de planificación urbana para mejorar y renovar el espacio rural (Camaioni y D’Onofrio, 2016). Es por ello que las bodegas han seguido siempre unas pautas estratégicas en su localización atendiendo a factores naturales y económicos principalmente.

En lo referente a la localización de las bodegas subterráneas, López Ocón (2015) destaca aspectos como la proximidad al núcleo urbano o la facilidad de construcción al aprovechar la inercia térmica del terreno y poder realizar la excavación en la tierra. Se utilizaban para la elaboración del vino y tenían carácter funcional. Estas bodegas son las más significativas y extendidas en el municipio de Borja.

3 Ministerio de Agricultura, Pesca y Alimentación, 2019. https://www.mapa.gob.es/es/cartografia-y-sig/publicaciones/alimentacion/mapa dop_vinos.aspx 
Por otro lado, las grandes bodegas industriales se dirigen a la obtención de economías de escala, reduciendo los costes unitarios. Se erigen en emplazamientos próximos a carreteras, en espacios con buenas comunicaciones, y cerca de los viñedos. Cabe esperar, por tanto, que tiendan a instalarse en lugares que permitan maximizar el potencial de distribución en espacios bien comunicados y accesibles.

Finalmente, muy orientadas a la producción de alta calidad y, también, como consecuencia del interés que ha despertado en las últimas décadas el turismo del vino, destacan las bodegas del modelo château (Aparicio Amador, Sánchez Hernández, Alonso Santos y Rodero González, 2008). Éstas últimas, tienden a emplazarse en entornos más idílicos y atractivos, habitualmente rodeadas de viñedo y parajes de gran belleza, que aprovechan para la organización de actividades de enoturismo (Miranda Escolar y Fernández Morueco, 2011; Plaza Tabasco, Cañizares Ruiz y Ruiz Pulpón, 2017).

La actividad vitivinícola, viñedos y bodegas, constituyen un binomio clave para comprender la historia socio-económica de la comarca de Borja y la organización de su territorio. La producción de vino ha estado presente en este espacio desde hace siglos y se ha convertido en un producto que, aparte de dinamizar y diversificar la economía local, contribuye a la creación de un sentimiento de identidad en torno a esta bebida y de arraigo en el territorio.

La evolución de esta actividad económica se ha ido transformando con el paso de los siglos, adaptándose a las nuevas coyunturas de mercado exigidas por los consumidores. La competencia del sector es cada vez más fuerte con un mayor número de vinos producidos en numerosas comarcas españolas, así como en otros territorios del mundo, que luchan por ser elegidos por los consumidores. Estas circunstancias que se han sucedido a lo largo del tiempo han repercutido en la industria y en el paisaje vitivinícola que ha tenido que adaptarse a los cambios que se iban produciendo.

Respecto a los viñedos, estas transformaciones han modificado los paisajes de la vid y el vino, pues han afectado a los tipos de variedades cultivadas, a los sistemas y los marcos de plantación; también, a los tipos de poda. Así mismo, más recientemente, como consecuencia del cambio climático, a su localización espacial, apareciendo la vid en lugares poco habituales hasta la fecha. Una situación similar ha ocurrido en el caso de las bodegas. Para poder hacer frente a las nuevas demandas del mercado y cumplir los reglamentos sanitarios, han experimentado notables cambios en sus instalaciones y emplazamientos.

Es aquí donde se enmarca este trabajo de investigación, y cuyo objetivo es analizar la lógica locacional de los diferentes tipos de bodega en el entorno de la ciudad de Borja. Para ello se ha considerado la distribución de las bodegas tradicionales excavadas en las laderas, también llamadas rupestres (Chueca Yus, 2004), las industriales y las nuevas bodegas surgidas al albur de la nueva cultura del vino. Se ha partido de la hipótesis de que cada tipo de bodega sigue unas pautas de localización propias y diferentes entre sí. Para dilucidar esta hipótesis se ha analizado la distribución de las bodegas en relación con su modelo productivo.

\section{Metodología}

El área de estudio se caracteriza por ser una zona histórica en la producción de vino y tiene como núcleo central la localidad de Borja, que ejerce de centro económico, social y cultural de este espacio. El Campo de Borja es desde 1980 una Denominación de Origen Protegida (DOP) de vino ubicada en la provincia de Zaragoza; dentro de ella, se ha analizado la distribución de las bodegas ubicadas en Borja y el entorno de Maleján (Figura 1).

Actualmente en la DOP Campo de Borja hay inscritas 18 bodegas $^{4}$ y 6.301 hectáreas de viñedo ${ }^{5}$, con dominio de la variedad garnacha, seña de identidad de la comarca. En la zona, existen referencias al viñedo documentadas por escrito en los archivos del Monasterio de Veruela desde el año 1203. Se trata de unas donaciones de viñas del área de Magallón al quinto Abad de Veruela, tal como recoge el pliego de la $\mathrm{DOP}^{6}$. Desde entonces y sin interrupciones la zona ha estado ligada a la producción de vino, por lo que la tipología de bodegas ha ido evolucionando con el paso del tiempo en función de los sistemas productivos.

En primer lugar, se ha elaborado una clasificación de las bodegas en función de su localización y, posteriormente, se ha puesto en relación con elementos tales como la topografía del relieve (laderas); el emplazamiento de los viñedos; la situación de los núcleos urbanos y de las vías de comunicación.

\footnotetext{
4 Consejo Regulador de la DOP Campo de Borja en 2020.

5 Ministerio de Agricultura, Pesca y Alimentación (MAPA) 2018.

6 Pliego de Condiciones de la DOP Campo de Borja, URL: https://www.mapa.gob.es/images/en/Campo_de_Borja_tcm38-211462.pdf
} 
Figura 1. Límites administrativos y distribución del viñedo en la DOP Campo de Borja

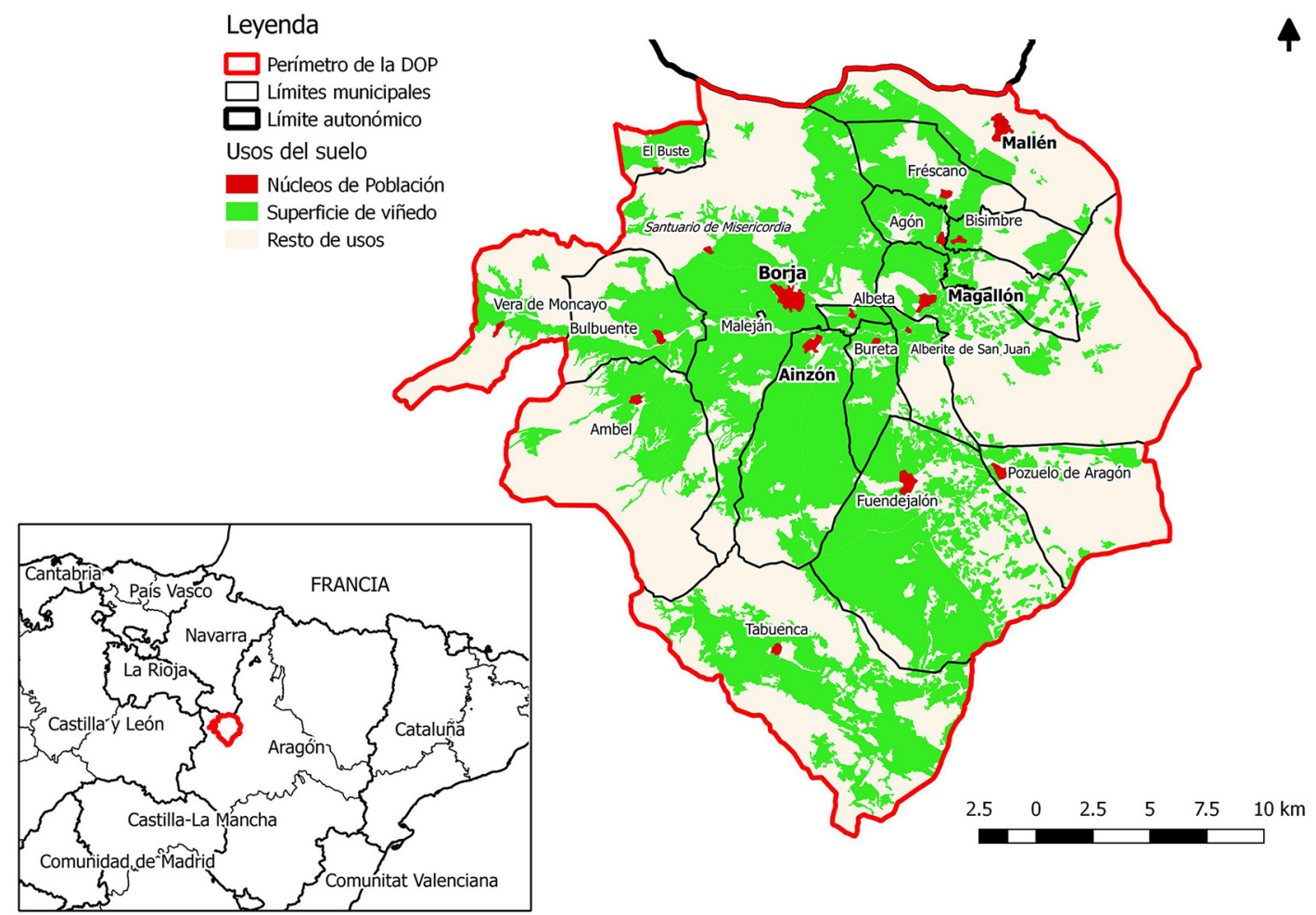

Fuente: Base Topográfica Nacional 1:100.000 y 1:500.000 del Instituto Geográfico Nacional (IGN), límites municipales (IGN) y polígonos con viñedo de la base de datos de ocupación del suelo en España (SIOSE) de 2014 (IGN). Elaboración propia

En el entorno de la ciudad de Borja se distinguen tres tipos fundamentales de bodegas:

- Bodegas "rupestres" excavadas en el suelo o en laderas y que se corresponden con un modelo de producción a pequeña escala, anterior a la industrialización. Se encuentran formadas por bodegas de reducidas dimensiones que eran abastecidas por pequeños viñedos.

- Bodegas asociadas al modelo de producción industrial. Son las bodegas cooperativas de gran tamaño fundadas con anterioridad a la creación de la DOP, o bien las bodegas derivadas de la fusión de éstas o sus comercializadoras. Predominan las economías de escala, por lo que pueden alcanzar una producción alta, competir en precios y abastecer mercados de gran tamaño.

- Bodegas creadas ex novo ${ }^{7}$, con posterioridad a la constitución de la DOP y que se asocian con una producción agroalimentaria de la más alta calidad. Se trata de bodegas de pequeño tamaño que producen vino orientado a mercados elitistas, y que se podría denominar "modelo interpersonal" (Sánchez Hernández et al., 2010). En este modelo, las características del producto tienen mayor protagonismo que el propio precio en cuanto a competencia entre empresas (Salais y Storper, 1992).

A la hora de elaborar la cartografía para conocer la disposición espacial de cada tipo de bodega, ha sido fundamental la información obtenida en documentos históricos; aquella proporcionada por vecinos del área de estudio y, en especial, el trabajo de campo. Los mapas resultantes son esenciales para poder comprender la lógica en el emplazamiento de este tipo de industria en sus orígenes y ver cómo ha evolucionado hasta la actualidad. Dentro de estos tres tipos de bodegas, para la elaboración de los mapas, se ha distinguido entre las bodegas rupestres sin actividad (pero con presencia física en el territorio), las bodegas que han desaparecido y aquellas que se encuentran operativas (con actividad comercial en la actualidad).

Para cartografiar las bodegas rupestres sin actividad se ha partido de un esquema de distribución de los principales focos de este tipo de bodega. Algunos de ellos ya estaban recogidos en el Mapa de Borja de

7 Bodegas creadas de forma independiente a las de tipo industrial en las que la calidad del vino tiene un papel predominante. Además, suelen ubicarse en entornos con calidad paisajística. 
1853 elaborado por Francisco Coello ${ }^{8}$. El esquema se ha elaborado teniendo en cuenta aquellas que son visibles desde la carretera o el núcleo urbano. Posteriormente, se ha complementado mediante entrevistas a miembros de la cooperativa, responsables de bodegas y vecinos. En estas reuniones se ha hablado con vecinos titulares de bodegas rupestres, miembros y antiguos responsables de la cooperativa y propietarios de bodegas creadas con posterioridad a la constitución de la DOP. Han consistido en entrevistas en profundidad, efectuadas tanto de forma presencial como telefónica. En ellas, además de ubicar las diferentes bodegas, se ha recogido información acerca de la evolución del sector, su situación actual y sus perspectivas de acuerdo a los nuevos modelos de producción.

La cartografía de las bodegas "rupestres" se ha realizado mediante fotointerpretación en campo, realizando una delimitación de áreas sobre imágenes del Plan Nacional de Ortofotografía Aérea (PNOA) de 2015. La resolución espacial de estas imágenes no permite diferenciar con suficiente detalle los elementos de la bodega. Por ello se ha realizado la fotointerpretación a partir del trazado que presenta la estructura de calles a diferentes cotas de los barrios de bodegas. Este trabajo se ha llevado a cabo en el campo, a la vista de la realidad del terreno, lo que ha permitido obtener información complementaria respecto a las características de las bodegas como es la orientación a saliente o poniente y las características de su arquitectura, en particular las fachadas y las lumbreras. También se han hecho anotaciones sobre el estado de conservación. El resultado obtenido en esta etapa de la investigación, si bien no es una cartografía exhaustiva de todas las bodegas rupestres, permite conocer la distribución general de las que se conservan en la actualidad.

Por otro lado, se encuentran las bodegas desaparecidas. Es posible que entre las bodegas rupestres algunas hayan desaparecido sin dejar constancia. Sin embargo, su distribución general es conocida por las que todavía se conservan, pues son muy numerosas. En cambio, la identificación de las bodegas desparecidas cobra mayor importancia en el caso de las primeras bodegas industriales instaladas en la zona que, a día de hoy, han cesado su actividad. La localización de estas últimas se ha identificado mediante información suministrada por los miembros de la cooperativa y los vecinos de la zona consultados.

Finalmente, las bodegas comerciales operativas, inscritas en la DOP, se han cartografiado a través de sus direcciones postales, verificando sobre el terreno la existencia de la bodega. Tras este proceso, se ha contactado telefónicamente con los responsables de las bodegas no cartografiadas correctamente. Éstas se han ubicado siguiendo las indicaciones del responsable. La Sociedad Cooperativa Agrícola de Borja es la bodega de mayor tamaño de todas las estudiadas y está compuesta por diversas naves. En este caso, se ha complementado la localización derivada de la información postal con fotointerpretación de sus principales instalaciones, utilizando como base imágenes del PNOA de 2018.

La distribución de cada tipo de bodega ha sido puesta en relación con otros elementos del territorio. En primer lugar, se ha considerado la aptitud del terreno para la construcción de bodegas. En segundo lugar, la proximidad a los núcleos de población y a los viñedos. Finalmente, en tercer lugar, se ha considerado el grado de accesibilidad, tomando como elemento de referencia la proximidad a infraestructuras viarias. Por ello, es necesario el uso de diversas fuentes para poder realizar el estudio y la cartografía.

En la zona de estudio predominan los relieves estructurales, siendo especialmente llamativa la muela de Borja. La muela enlaza a través de un relieve escalonado con el valle del río Huecha. Dado que es frecuente que las bodegas rupestres se encuentren ubicadas en las laderas de los cerros (Chueca Yus, 2004), la distribución de este tipo de bodegas se ha puesto en relación con el mapa de pendientes derivado del modelo digital del terreno con paso de malla de $5 \mathrm{~m}$ del Centro Nacional de Información Geográfica ${ }^{9}$. Así mismo, la distribución de las bodegas se ha puesto también en relación con un mapa de orientaciones derivado del mencionado modelo digital del terreno. La extensión de los núcleos de población ha variado con el tiempo. Este hecho se pone de manifiesto comparando el mapa de Borja en 1853 elaborado por Coello y la distribución de la cartografía catastral actual ${ }^{10}$. Pese a ello, en lo sustancial no ha habido grandes modificaciones, pues ninguna de las cabeceras municipales ha sido abandonada. Teniendo en cuenta estas consideraciones, se ha analizado la distribución de las bodegas atendiendo a la distribución actual de los núcleos de población.

8 Zaragoza (Provincia). Mapas generales. 1853. Zaragoza [Material cartográfico] por el Teniente Coronel, Capitán de Ingenieros Francisco Coello. Notas estadísticas e históricas escritas por Pascual Madoz; contorno por Raynaud; topografía por Labreton; y letra por Bacot. Escala 1:200.000 [Imp. Atlas de España], Madrid, 1853. № 0244 del catálogo de Fondos Cartográficos del IGN, publicado en el año 2000. Signatura 30-C-8.

9 Modelo Digital del Terreno (5 metros) de España MDT05/MDT05-LIDAR Instituto Geográfico Nacional (IGN) http://centrodedescargas. cnig.es/CentroDescargas/busquedaSerie.do? codSerie=MDT05

10 Servicio WMS INSPIRE de la DG de Catastro. http://ovc.catastro.meh.es/cartografia/INSPIRE/spadgcwms.aspx 
El viñedo, con 6.274 ha ${ }^{11}$ en la comarca, tiene gran presencia en el área de estudio. La disposición de las bodegas se ha puesto en relación con la distribución del cultivo utilizando como fuente de información la base de datos de ocupación del suelo en España (SIOSE) de 2014 (IGN).

Finalmente, se ha tenido en cuenta la accesibilidad y, en especial, la relación de proximidad a los ejes de comunicación, como una pauta que influye en la actualidad a la hora de elegir el emplazamiento de las bodegas. En el área de estudio existe una carretera de la red principal, se trata de la Nacional 122 que enlaza Aragón con Castilla y León, especialmente importante en las comunicaciones entre la provincia de Soria y la de Zaragoza. Asimismo, en la zona de estudio se cuenta con 2 carreteras de segundo orden. La primera de ellas es la A-1303 que va de Borja a Ainzón y enlaza con el Jalón. La segunda, la A-1301, comunica Ainzón con Tabuenca. Por otro lado, al norte de Borja se encuentran la CV-606 que se dirige hacia el Santuario de Misericordia y El Buste y la CP-2 hacia Mallén y Cortes. El trabajo realizado ha consistido en poner en relación la distribución de las bodegas con la distancia a cada uno de estos viales siguiendo la clasificación presente en la cartografía de vías de comunicación del IGN ${ }^{12}$.

\section{Resultados}

La exposición de los resultados comienza por una descripción de la distribución general de las bodegas en el área de estudio. Posteriormente se analiza cada tipología en función de los elementos con los que se asocia su instalación y, por último, se analiza la evolución que han seguido a lo largo del tiempo en función de los cambios tecnológicos y del paradigma agroalimentario.

En el área de estudio los tipos de bodega analizados ocupan espacios diferenciados (Figura 2). Las bodegas rupestres se encuentran fundamentalmente en las laderas de los cerros ubicados en las proximidades de los núcleos urbanos de Borja y Maleján, mientras que las bodegas de corte industrial se encuentran próximas al espacio urbano y los polígonos industriales.

Figura 2. Localización de las bodegas en el entorno de la ciudad de Borja

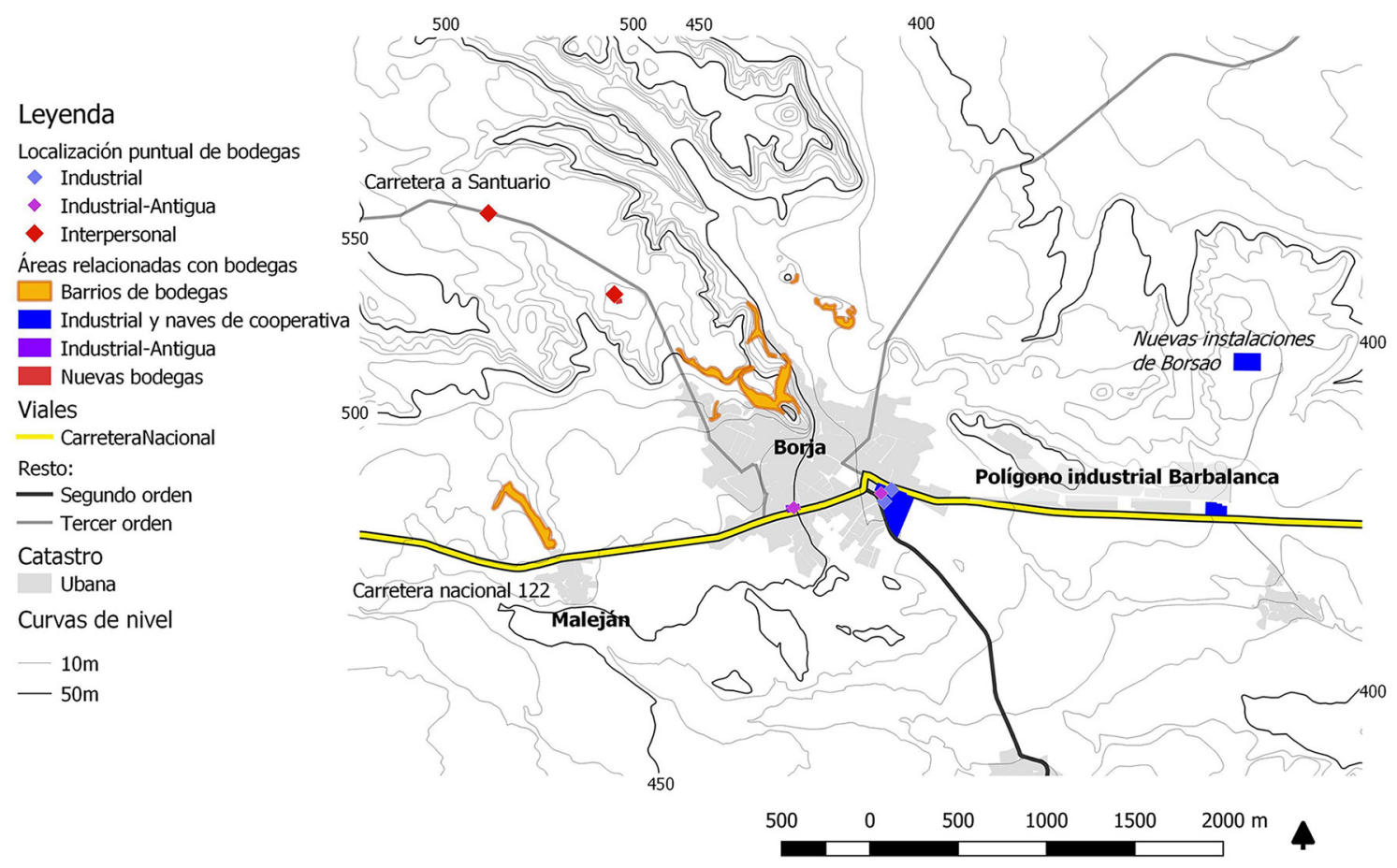

Fuente: Cartografía de parcelas urbanas (Catastro) y base topográfica del IGN a escala 1:25.000. Elaboración propia. En la cartografía de bodegas industriales se han incluido las dependencias de la Cooperativa Agrícola de Borja en el polígono Barbalanca

11 Instituto Aragonés de Estadística: distribución general de tierras, cultivos leñosos por comarcas (2017). https://aplicacionesportalaragon. aragon.es/tablas/iaest/areas-tematicas/08-agricultura-industria-construccion/agricultura-ganaderia-selvicultura-y-pesca.html

12 Información Geográfica de Referencia - Redes de Transporte 2017 - Instituto Geográfico Nacional (IGN) - http://centrodedescargas.cnig. es/CentroDescargas/ 
Atendiendo a la disposición del viñedo en el área de estudio, ambas tipologías se encuentran cercanas al mismo. Sin embargo, las bodegas de corte industrial, a diferencia de las bodegas rupestres no se localizan en las laderas. Lo hacen en torno a la carretera nacional que atraviesa la zona, donde cuentan con mayor accesibilidad, lo que permite un correcto desarrollo de las tareas que en ellas se desarrollan. Las bodegas industriales antiguas, ya desaparecidas, ocupaban una posición similar en el mapa a las nuevas, junto a la carretera, lo que facilitaba el transporte y la comunicación.

El desarrollo que han tenido las bodegas de corte industrial, a causa del crecimiento de este sector económico, las ha llevado a crear a partir del año 2015, naves auxiliares para poder hacer frente a las nuevas demandas de los mercados. Estas naves, aunque se han ubicado cerca del polígono industrial, lo han hecho en un entorno relativamente elevado. La tendencia a ubicarse en este tipo de espacios también se aprecia en las nuevas bodegas de corte elitista. Tienden a situarse alejadas del espacio urbano, rodeadas de sus viñedos y en un entorno con mayor valor paisajístico de cara a un eventual desarrollo del enoturismo. En el caso de Borja se ubican en la carretera que une el núcleo de Borja con el Santuario de Misericordia.

\subsection{Bodegas rupestres. El medio físico como factor condicionante para su emplazamiento}

La construcción de bodegas rupestres era muy frecuente a finales del siglo XIX y se recogen en el mapa de Coello de 1852 (Figura 3). Se encuentran ubicadas eminentemente, como se ha comentado, en las laderas del castillo. Su construcción, según las entrevistas realizadas a vecinos de la localidad implicados en la actividad vitícola desde hace décadas, tenía lugar en determinados periodos del año. Las bodegas bajo tierra solían construirse en invierno y eran los propios propietarios, pequeños viticultores, los encargados de su construcción; estaban destinadas a la elaboración de vino que comercializaban de forma independiente.

Figura 3. Mapa del municipio de Borja de 1853 elaborado por Francisco Coello. Emplazamiento de las bodegas rupestres

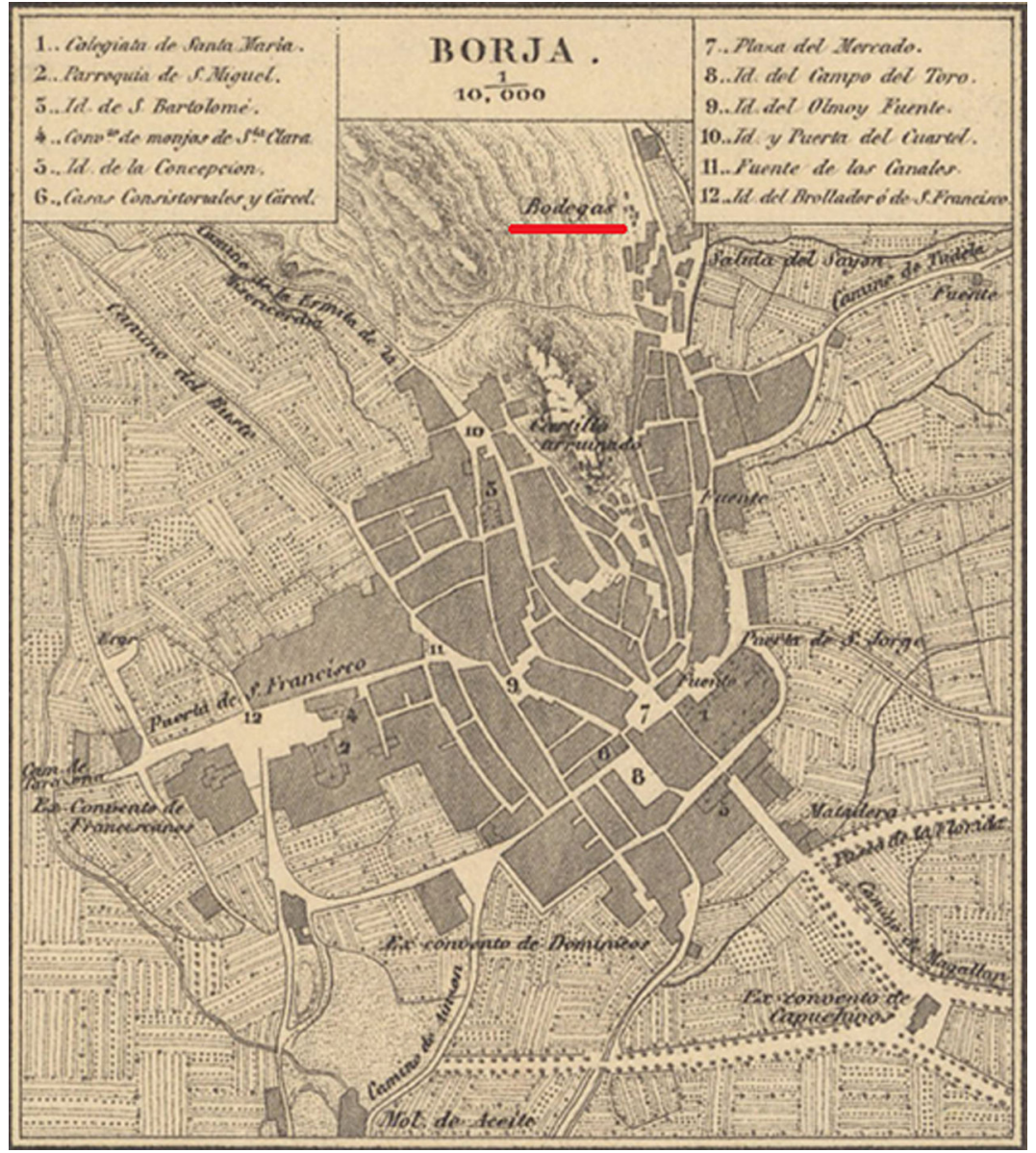

Fuente: Catálogo de Fondos Cartográficos del IGN 
Las bodegas rupestres en el área de estudio se ubican próximas a los núcleos urbanos, en concreto, en las laderas (Figura 4). La tipología constructiva que predomina es la de las cuevas vinarias excavadas aprovechando la topografía inclinada que ofrecen los oteros y los cerros testigos, especialmente a los pies del Castillo de Borja y en su entorno (Figura 5) y, en menor medida, en torno a Maleján. Esta ubicación responde a la facilidad con la que estas pendientes permiten realizar los trabajos de excavación. Además, se trata de un emplazamiento con buena accesibilidad al centro urbano, lo cual facilitaba que se pudieran llevar a cabo labores de mantenimiento y la función comercial, pues todo el modelo de gestión dependía del viticultor, llevando a cabo todo el sistema productivo: cultivo de la vid, elaboración del vino y venta del producto.

Figura 4. Relieve y distribución de bodegas rupestres

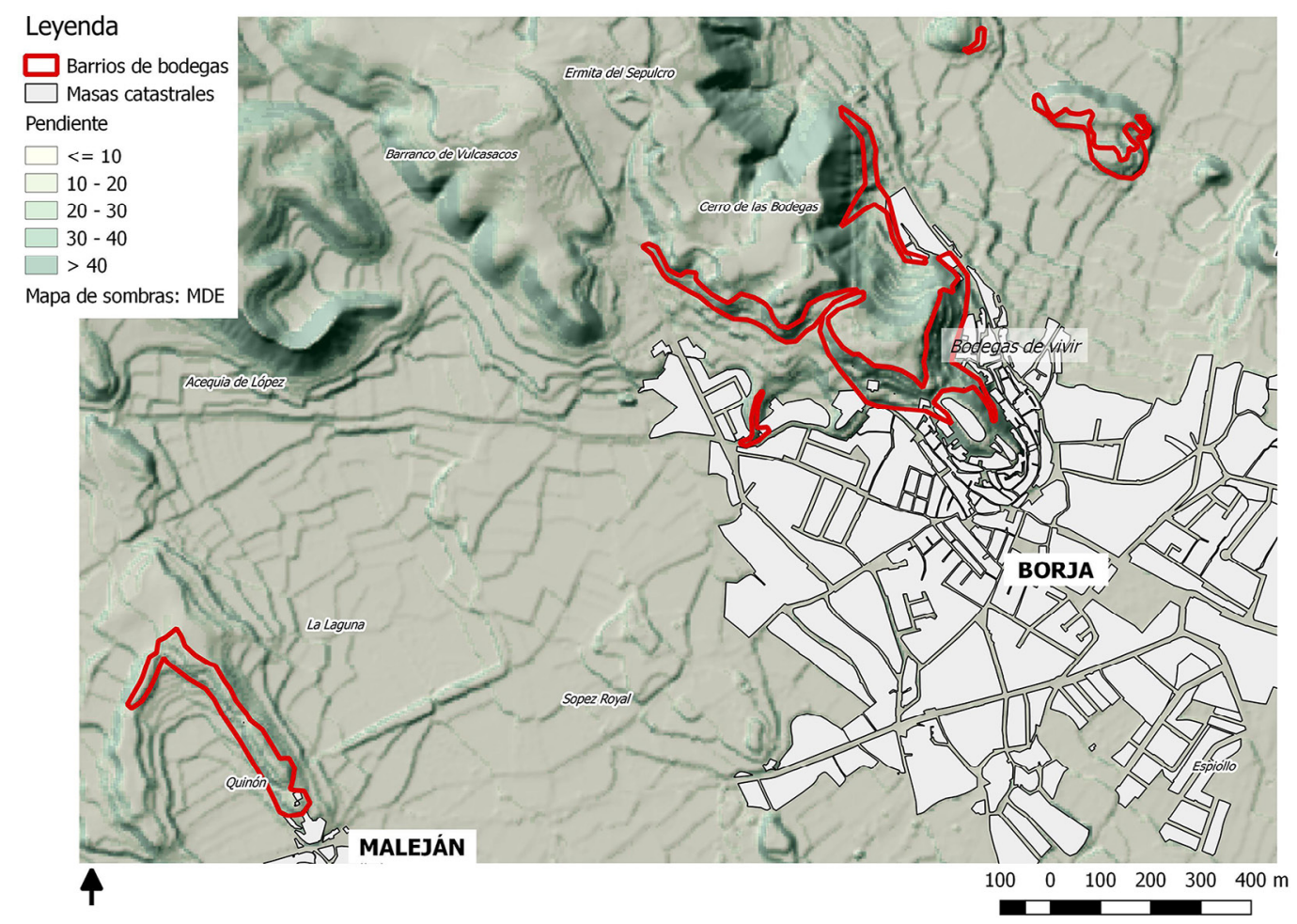

Fuente: Masas de Catastro, toponimia NGBE, modelo de elevaciones del IGN. Elaboración propia

Figura 5. Bodegas rupestres en Borja

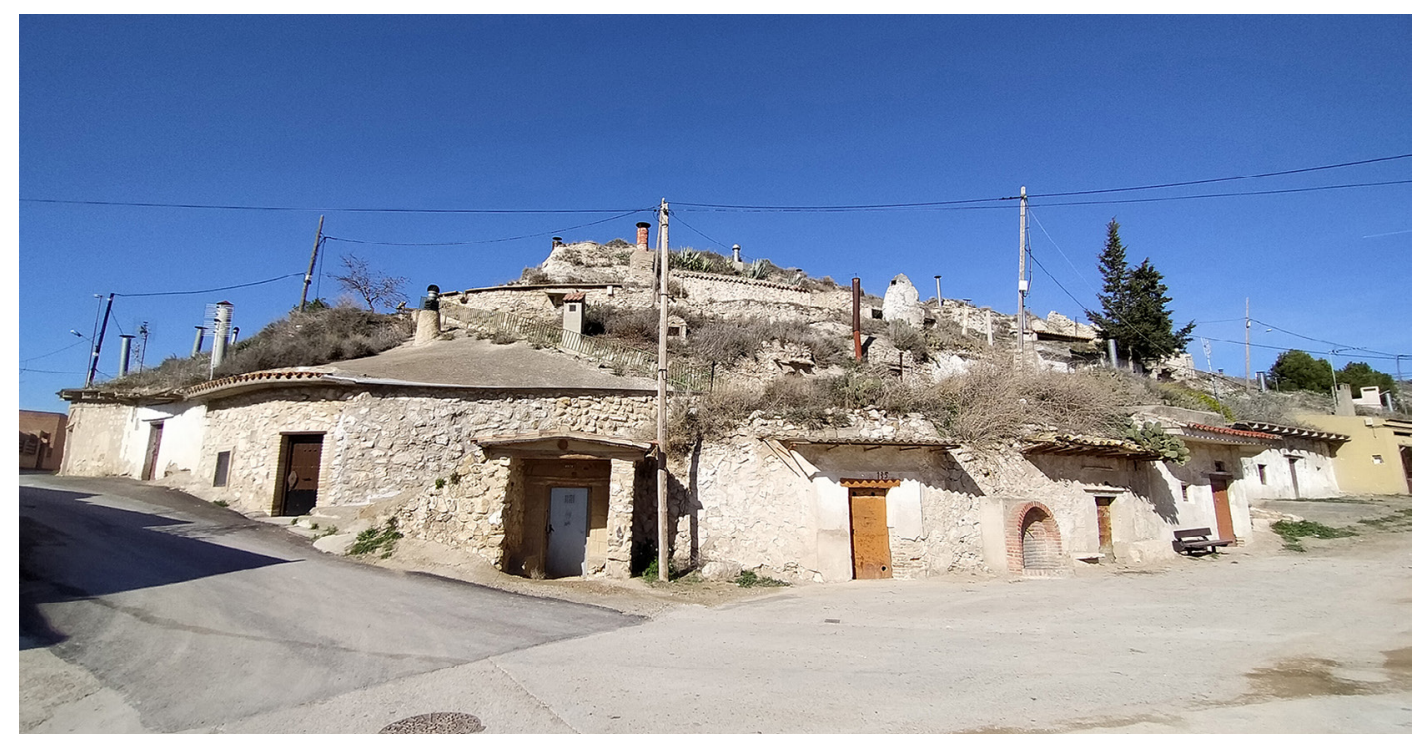

Fotografía de los autores 
En el núcleo de Borja existen dos zonas de bodegas rupestres, las de poniente y las de saliente (Figura 6). Las primeras se encuentran orientadas hacia el Moncayo, en dirección oeste y las de saliente se orientan hacia el levante y se ubican eminentemente al este del castillo de Borja. En el entorno de Maleján, la orientación predominante de las bodegas es de poniente. Algunos de los vecinos de la zona entrevistados han señalado que la disposición preferida de las bodegas para desarrollar la actividad vinaria era la que contaba con orientación al oeste, por considerarse más fresca y saludable para la uva. Es por ello, que la mayor parte de las bodegas se encuentran mirando al Moncayo. Pese a que en este trabajo no se ha realizado un censo exhaustivo, se ha cartografiado un total de 12,23 ha de bodegas, de estas, un 57,39\% cuenta con una orientación predominante a poniente y un $42,61 \%$ a saliente.

Figura 6. Orientación de las bodegas rupestres

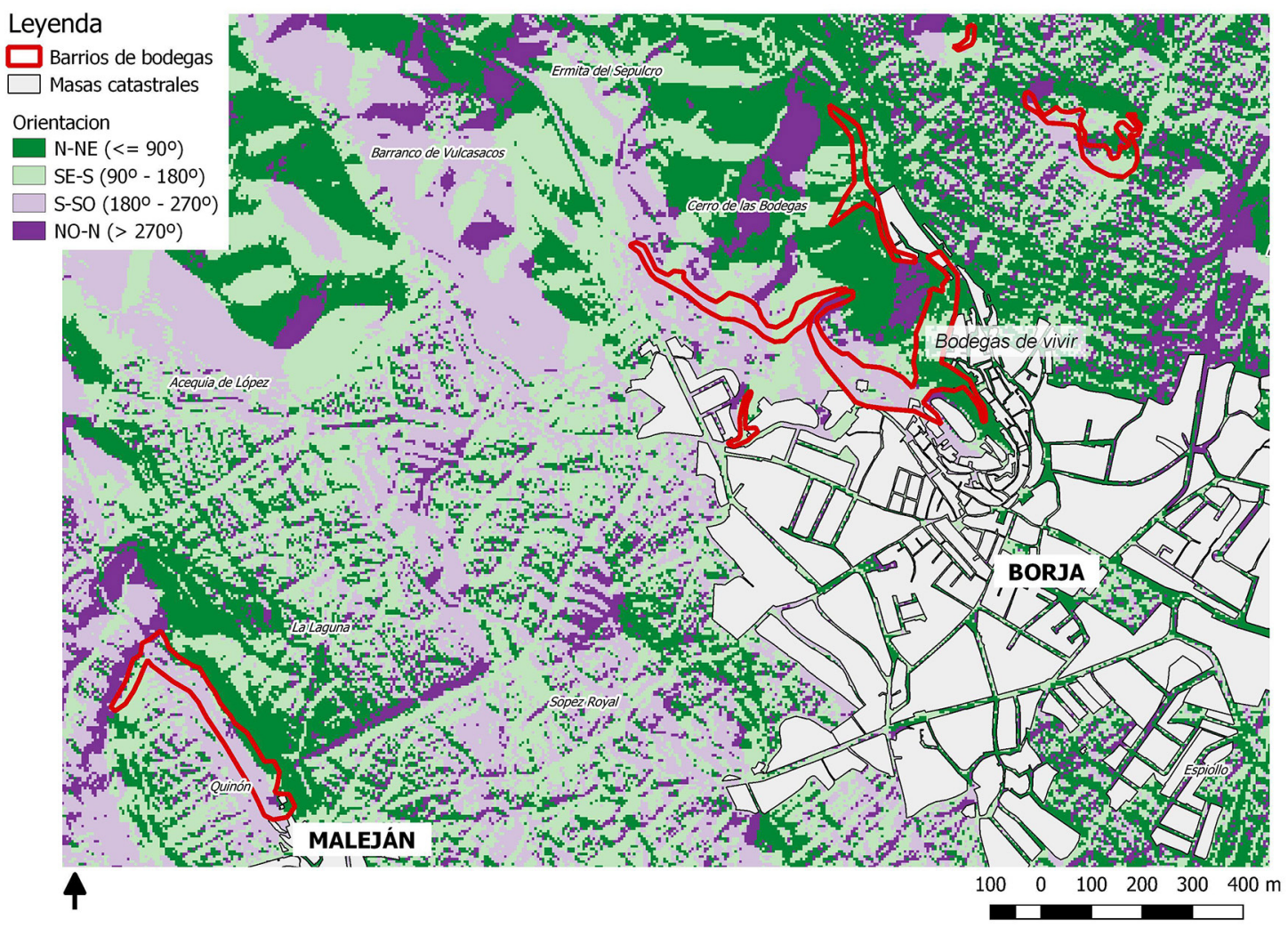

Fuente: masas de catastro, toponimia NGBE, modelo de elevaciones del IGN. Elaboración propia

En Borja existe una zona donde predominan las casas-cueva o "bodegas de vivir". Se trata de bodegas integradas en el núcleo urbano y que han sido utilizadas como casas. Las bodegas de vivir inicialmente respondían a la función de bodega, pero después adoptaron un uso residencial. Entre las causas de esta reconversión se encuentra su localización, integrada en la Ciudad de Borja; generalmente, su tamaño era mayor que el de otras bodegas. Además, las bodegas para vivir cuentan predominantemente con una orientación este. Tal como se ha mencionado, algunos vecinos han mostrado una opinión más favorable para la actividad vinaria en las bodegas con orientación oeste. Esta consideración también puede haber contribuido al cambio de uso que experimentaron estas instalaciones. Uno de los vecinos entrevistados señaló que nació en una bodega a inicios de la década de 1960, por lo tanto, este uso residencial llega a solaparse en el tiempo con el proceso de creación de cooperativas. La existencia, con diferentes grados de ocupación, de "bodegas de vivir" integradas en el espacio urbano se ha mantenido hasta la actualidad. Sin embargo, en la mayor parte de los casos, ha desaparecido el uso residencial de carácter permanente.

El estado de conservación actual de las bodegas rupestres varía en buena medida en función de su accesibilidad, tal como se ha constatado en el trabajo de campo. Las bodegas mejor conservadas están bien integradas en el espacio urbano y son numerosas las bodegas que se han reconvertido en merenderos familiares. Este tipo de usos ha evitado su deterioro, pues cuentan con un mantenimiento que no presentan muchas bodegas, especialmente en las cotas más elevadas, muchas de las cuales se encuentran incluso 
en riesgo de derrumbamiento. Pese a esto, en la actualidad, todavía existen bodegas donde se elabora vino destinado al consumo del propietario, como se pudo comprobar durante el trabajo de campo tras la vendimia. Prueba de ello son los restos de hollejo que atestiguan esta actividad y el aroma que había esos días por el barrio de bodegas.

Sin embargo, las transformaciones acaecidas en este sector agroindustrial han dado lugar a un cambio en el sistema productivo al trasladar los centros de elaboración de vino a las bodegas industriales. Estas son capaces de elaborar el vino siguiendo las exigencias establecidas en los reglamentos sanitarios y de los consejos reguladores, por lo que las bodegas tradicionales han quedado relegadas a elementos de la arquitectura tradicional, empleadas como merenderos, y en otras comarcas vitivinícolas como restaurantes y museos y, en el peor y más habitual de los casos, olvidadas a pesar de haber sido la base de la industria vinícola actual.

\subsection{Bodegas industriales. El papel de la accesibilidad en su localización}

Las bodegas industriales están ubicadas próximas al núcleo de población y al polígono industrial. La localización está claramente definida por la accesibilidad a la carretera nacional, eje de comunicación que facilita tanto la recepción de la uva como la distribución del producto elaborado.

La industrialización modificó el proceso tradicional de producción y comercio del vino. Se pasó de la elaboración y comercialización llevada a cabo por pequeños productores en un ámbito de carácter local y regional, a cobrar una mayor importancia las bodegas de mayor tamaño a cargo de sociedades y cooperativas con una expansión de los mercados hacia el ámbito nacional e internacional que han adquirido un matiz clave en la dinámica económica de estas empresas. Los pequeños bodegueros no podían afrontar las nuevas inversiones que necesitaba el sector productivo de forma individual como, por ejemplo, la propia construcción de estas instalaciones, la implantación de maquinaria como son los depósitos de almacenaje del vino, las líneas de embotellado o laboratorios para llevar a cabo el control del vino. Unos cambios que han afectado al modelo de gestión, pues, anteriormente, el bodeguero se encargaba de todo el proceso productivo y ahora es necesaria la especialización dentro de la bodega, pero también en el campo, que permita llevar a cabo los diversos trabajos requeridos y por ende, la necesidad de mayor mano de obra, dejando fuera de estas tareas a la ayuda familiar tan valiosa para el pequeño viticultor y bodeguero.

El avance de la industrialización propició un proceso de concentración y se crearon nuevas bodegas industriales en el entorno de la carretera y de mayor tamaño. El cambio más significativo se produjo en la década de 1950 por parte del sindicato de agricultores con la creación de la Cooperativa Agrícola. Esta asociación autónoma de personas adquirió una de las bodegas industriales creadas con anterioridad. Desde entonces se fue expandiendo hasta tal punto que, incluso, una de las bodegas tradicionales de mayor tamaño se integró en ella, lo que muestra el proceso de cambio, tanto de gestión como de producción, desde unas bodegas a otras para poder hacer frente a la expansión de los nuevos mercados que se estaban abriendo en el territorio como consecuencia del aumento en el consumo de vino y con unos estándares de calidad cada vez más elevados.

Las primeras instalaciones de corte industrial, actualmente desaparecidas, se localizaron desde un primer momento en la carretera que enlaza las provincias de Zaragoza y Soria, en lo que entonces era una zona de expansión urbana que todavía no se había desarrollado (Figura 7). En la actualidad, las bodegas industriales operativas de la zona de estudio, como la cooperativa, continúan localizadas en torno al mismo eje de comunicación. La expansión de este tipo de bodegas tiende a ocupar las áreas próximas a la carretera, en el entorno del polígono industrial. En esta decisión juega un papel estratégico la accesibilidad de las instalaciones a través del transporte por carretera para dar salida con mayor rapidez y facilidad a los vinos.

También es significativo destacar que actualmente la construcción y la tipología arquitectónica de las bodegas es muy diferente a las rupestres, pues no depende del trabajo manual e individual de un pequeño productor. Son empresas en ocasiones familiares, pero, en otros casos, se trata de inversiones de grandes grupos empresariales. Se construyen con nuevos materiales y maquinaria moderna adecuada para la elaboración y conservación del vino, y siguen los planes trazados a tal efecto por técnicos y arquitectos. Se construyen espacios adecuados a los nuevos métodos de vinificación, y, en ocasiones, pensando en el desarrollo de nuevas actividades económicas orientadas hacia el turismo del vino. 
Figura 7. A) Localización de las bodegas de corte industrial. Bodegas industriales desaparecidas. Ortoimagen vuelo americano 1956. B) Localización de las bodegas de corte industrial. Bodegas industriales operativas. Ortoimagen del PNOA 2018
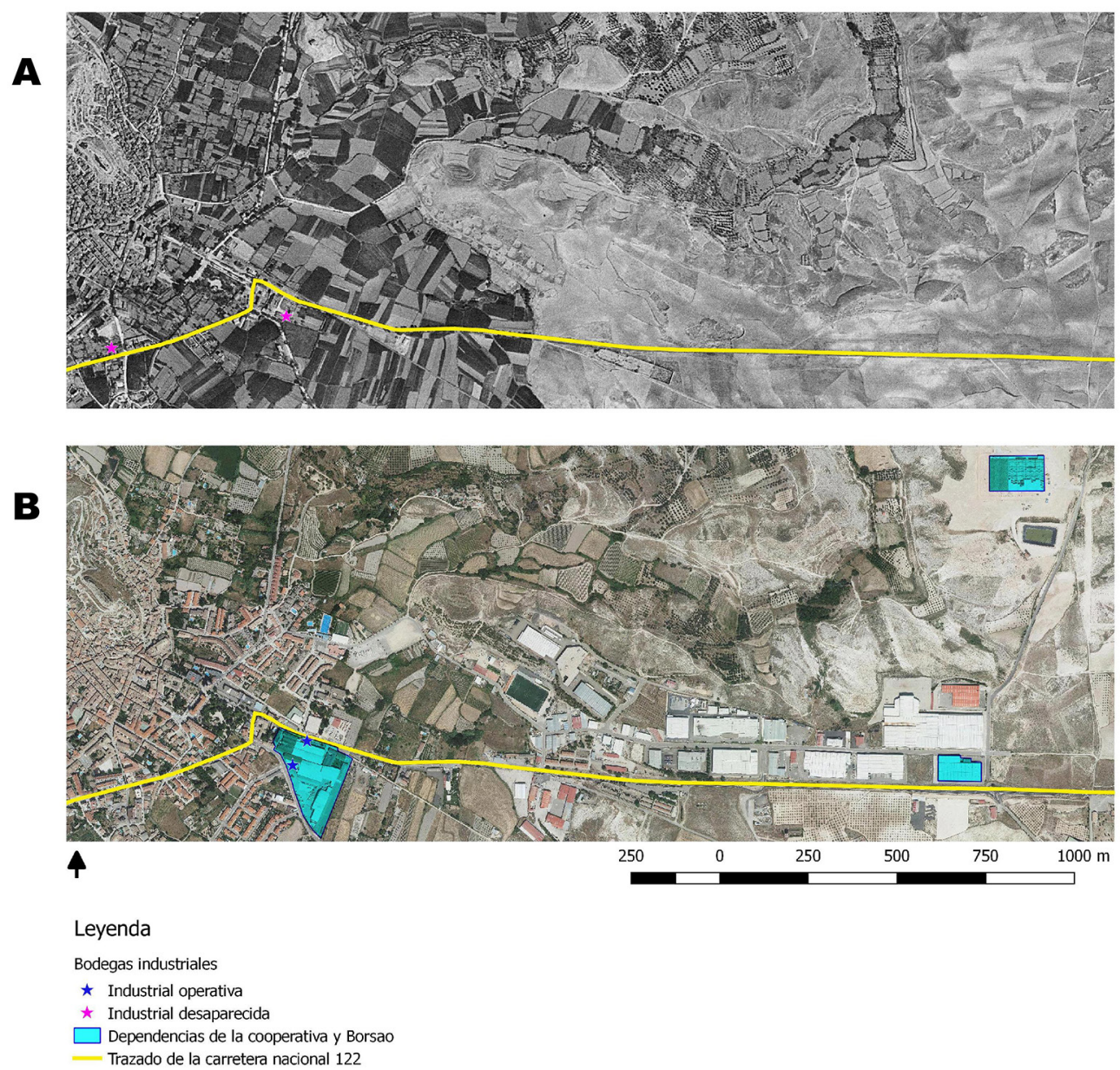

Fuente: Fondo en distribución de bodegas antiguas: orto-imagen del vuelo americano de 1956 (SITAR-CECAF). Fondo en distribución de bodegas operativas: orto-imagen de 2018 (PNOA). Elaboración propia en base a IGN

Las instalaciones de bodegas industriales en Borja ocupan una gran extensión superficial. Las dependencias que se han cartografiado de la cooperativa y Borsao suponen 5,86 ha destinadas a la producción, almacenaje y distribución de vino, en torno a un $86 \%$ de la superficie de sus naves, el resto corresponde a otra nave ubicada en el polígono y que está fundamentalmente dedicada a cereales, almendras y a la producción de aceite.

La nave central de la cooperativa se encuentra entre la Nacional 122 y la carretera autonómica 1303 que une Borja con Ainzón y otros municipios de la DOP de Campo de Borja. Esta nave es una ampliación de aquella primitiva bodega industrial que fue adquirida por la cooperativa, habiendo alcanzado una superficie de 3,5 ha de instalaciones y es dónde se elabora la mayor parte del vino del área de estudio. Tiene una capacidad productiva de aproximadamente 9 millones de kilogramos y una cifra de negocio de en torno a 8 millones de euros. El gran volumen de uva y vino que moviliza justifica el emplazamiento de sus instalaciones en lugares accesibles que facilitan todo el proceso productivo y su posterior comercialización (Figura 8).

En 1981, después de constituirse la DOP, se crea la marca Borsao, con la que se comercializa el vino de la cooperativa, y en 2001 se unen las cooperativas de Borja, Tabuenca y Pozuelo, lo que da lugar a Bodegas Borsao S.A. con una ampliación de sus instalaciones en el polígono para poder hacer frente a las nuevas necesidades de la empresa. Una unión que va a facilitar la expansión a mercados internacionales exportando en torno al 70\% de su producción, una cifra elevada que conlleva la necesidad de personal especializado en la comercialización del vino en grandes mercados y que sería difícil si no se hubiera producido esta unión de bodegas. 
Figura 8. Vista de accesos a las naves de la cooperativa (ahora Borsao)

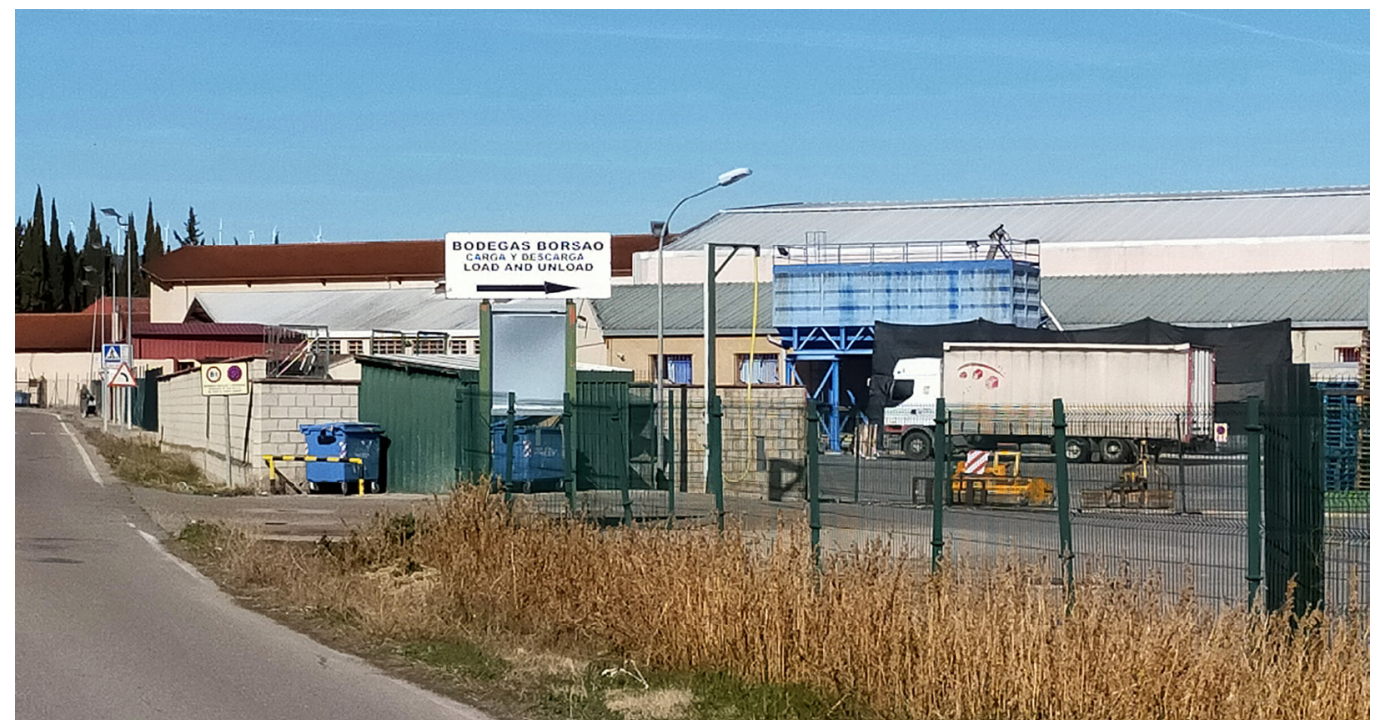

Fotografía de los autores

Las nuevas instalaciones de Borsao, aunque efectivamente se localizan en la zona baja del término municipal, están próximas al polígono industrial y son accesibles desde la carretera. El nuevo edificio que se ha construido se ubica en un entorno más elevado, que permite disfrutar de un amplio paisaje y su estructura y estética se aleja de las tradicionales naves propias de los polígonos industriales (Figura 9). Esta bodega, pese a heredar características del modelo industrial derivadas de las cooperativas que la integran, tiene elementos que la singularizan: unas naves donde se utiliza el ladrillo y la teja para su construcción, integradas con el entorno, en contraposición del hormigón y la chapa; una entrada más amplia con espacios diferenciados para el aparcamiento de los vehículos de los trabajadores y posibles visitantes; espacios ajardinados; zonas destinadas al ámbito laboral de recepción de tractores y camiones; accesos que comunican la carretera con la vía principal; también cuenta con dos espacios contrastados como son el edificio de administración y servicios y las naves para elaborar y almacenar el vino. Se observa un nuevo cambio en el modelo productivo de las bodegas, donde la arquitectura adquiere un papel importante. Las bodegas se mantienen como grandes espacios productores de vino, cada vez más especializados y desempeñando funciones acordes a la situación de los mercados y a los gustos de los consumidores. Se cuida más la estética del edificio y de su entorno, por lo que se emplazan en lugares cercanos a los viñedos o con altos valores ambientales.

Figura 9. Nuevas instalaciones de la bodega Borsao s.a.

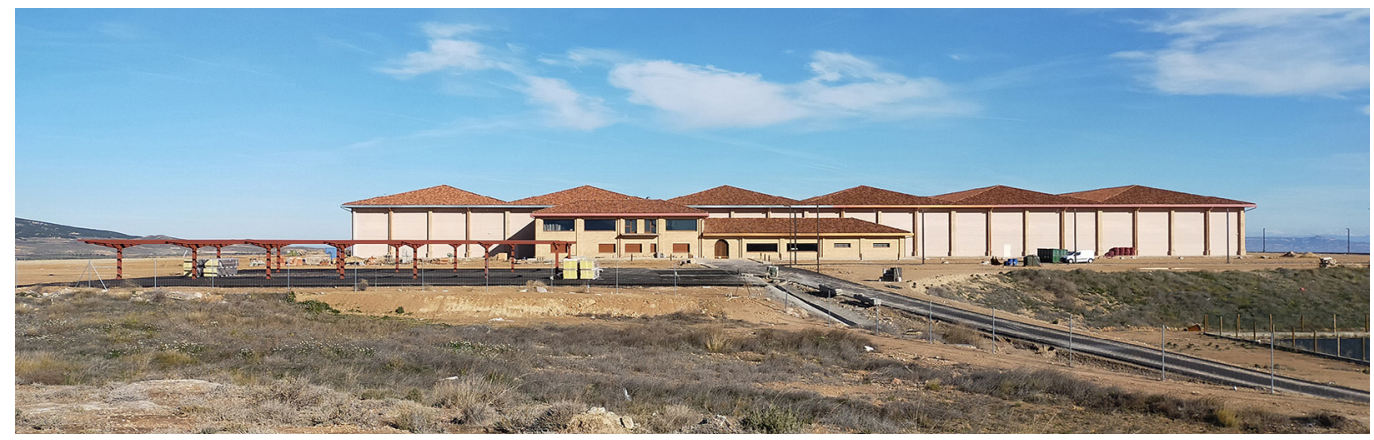

Fotografía de los autores

\subsection{Bodegas creadas ex novo con posterioridad a la DOP. Los nuevos escenarios del vino}

El auge del reconocimiento de la garnacha en el mercado ha impulsado la creación de nuevas bodegas especializadas en este tipo de uva. Se relacionan de una forma más directa con las nuevas iniciativas de corte elitista que se han instalado en la zona. 
Estos espacios productores se caracterizan por una producción de la más alta calidad ${ }^{13}$, un precio medio-alto ${ }^{14}$ y un pequeño tamaño de la bodega ${ }^{15}$. Su localización ha adoptado unas pautas singulares, pues se encuentran alejadas del núcleo urbano y no se encuentran en la carretera nacional, aunque si en sus inmediaciones. Además, su emplazamiento está en la parte alta del término municipal, desde dónde se pueden apreciar vistas panorámicas del Moncayo y otras zonas de la comarca, lo que se convierte en un recurso atrayente de cara a la visita de turistas. Se encuentran más próximas a la muela de Borja, un relieve estructural a cuyos pies se ubica un terroir que produce vino de una calidad especialmente alta (Lorente Blasco, 2017). Por otro lado, el eje viario dónde se encuentran no une Borja con las capitales de su entorno, sino que se trata de la carretera que enlaza Borja con el pequeño núcleo de El Buste y con el Santuario de Misericordia. Priman otro tipo de requisitos como el citado paisaje y valores de carácter ambiental, y dejando en un segundo plano las grandes elaboraciones de vino por otras más personales.

Precisamente su menor tamaño las hace menos dependientes de lugares próximos a la carretera, que sean fácilmente accesibles por parte de grandes camiones. Permite adoptar nuevas ubicaciones, regresando a enclaves elevados del término como sucedía con las bodegas rupestres. Es probable que la ubicación de estas bodegas se realice, entre otros factores, de cara a una eventual actividad enoturística, la cual está creciendo de forma considerable en esta comarca vitivinícola ${ }^{16}$. Sin embargo, de momento, ninguna de ellas desarrolla este tipo de actividades en la fecha de realización de este trabajo. Uno de los propietarios planteó, de cara al futuro, poder crear una sala de catas dentro de la bodega y realizar visitas y eventos. Unas iniciativas cada vez más frecuentes en la industria vitivinícola y que en algunos casos, requieren cambios en el modelo de bodega existente hasta la fecha, cuyo único fin era la elaboración del vino. La actividad industrial sigue siendo el eje económico, pues sin vino no hay ninguna otra actividad, pero el sector servicios está adquiriendo mayor relevancia con la diversificación de funciones, centradas en el enoturismo.

En cuanto a la localización el propietario entrevistado pone de manifiesto que en su caso la accesibilidad desde la carretera nacional no es un elemento determinante para el emplazamiento de la bodega. A este respecto señala que su bodega está orientada a una producción de alta calidad, no tanto a la comercialización de grandes volúmenes de vino.

En estos casos, en la elección del emplazamiento juega un papel más importante la disponibilidad de terrenos y el hecho de disfrutar de un paisaje agradable. Algunas de ellas como Bodegas Morca, tienen vistas al Moncayo. En cuanto a la proximidad al viñedo, propio de algunas bodegas elitistas, ponen de manifiesto la importancia de contar con viñas elegidas por su calidad más allá del hecho de que puedan o no rodear la bodega. Este hecho viene determinado por las características de la distribución del terroir del Campo de Borja y por la existencia de pequeñas parcelas dispersas de viñedos de alta calidad, con unas características específicas respecto a otros majuelos en lo concerniente a la variedad, al sustrato o al año de plantación de las vides.

Además de la panorámica que se ofrece de estas instalaciones, las bodegas se integran de forma armoniosa en el paisaje y, aunque funcional, cuentan con una arquitectura que intenta ir más allá de las tradicionales naves formadas por paneles de hormigón. Entran en juego diversos materiales como el cristal, la madera, el acero o el ladrillo. Están mejor integradas en el paisaje y son más atractivas de cara a la organización de visitas (Figura 10). A pesar de estos diseños, todavía se encuentran lejos de las corrientes vanguardistas de la enoarquitectura o arquitectura del vino como se está viendo en otras zonas vitivinícolas españolas como Rioja, Ribera del Duero o Somontano, donde se han erigido "templos del vino" a cargo de arquitectos de reconocido prestigio internacional como Richard Rogers, Santiago Calatrava, Frank Gehry o Norman Foster. Aun así, estas bodegas están cambiado el paisaje de la vid y el vino y contribuyen a la creación de un vínculo entre el lugar de producción y el producto.

13 Es frecuente que estas bodegas obtengan puntuaciones superiores a los 90 puntos en publicaciones nacionales como la Guía Peñín o internacionales como las de Robert Parker o Wine Spectator.

14 La Bodega Alto Moncayo ofrece vinos que oscilan entre los 23 y los 110€/botella y la Bodega Morca entre 15 y $100 € /$ botella (Anuario de vinos El País, 2019).

15 A modo de ejemplo, la Bodega Alto Moncayo, que pertenece a esta tipología, cuenta con 95 ha de viñedos frente a las 2.372 de Borsao (Anuario de vinos El País, 2015). La bodega de esta tipología de más reciente creación, Bodegas Morca, cuenta con 80 ha (Anuario de vinos El País, 2019).

16 La Ruta del vino de la Garnacha-Campo de Borja se ocupa de dinamizar el territorio de esta comarca. El número de visitantes se ha incrementado de forma considerable al pasar de los 4627 en el año 2013 a los 56821 en el año 2018. Datos obtenidos de ACEVIN. Rutas del Vino de España. 


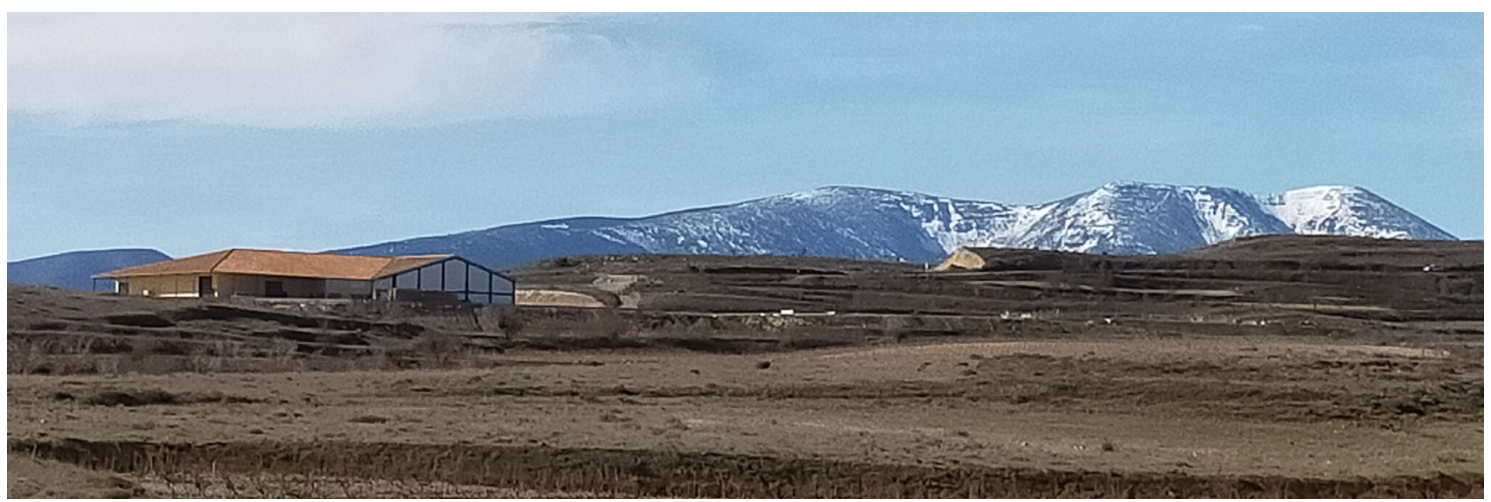

Fotografía de los autores

\subsection{Efectos de los cambios de modelo productivo en la ubicación de las bodegas}

Las bodegas son un claro ejemplo de adaptación a las trasformaciones industriales sufridas en cada momento histórico. El enclave de sus instalaciones ha cambiado con los años. Las rupestres aprovecharon los desniveles y los materiales blandos del cerro del castillo que facilitaba su construcción. Las de corte industrial tienden a concretarse a lo largo de los ejes de comunicación, en este caso de la N-122, para facilitar la llegada de vehículos de mayor tamaño que transportan manufacturas necesarias para el desarrollo de la actividad vínica y para el transporte del vino final embotellado. Por último, las nuevas bodegas de corte elitista, más recientes, tienden a ubicarse en las zonas altas del área de estudio adquiriendo mayor peso el valor paisajístico.

Existen dos cambios esenciales que determinan las pautas de localización de las bodegas (Figura 11). El cambio inicial se produce en la primera mitad del siglo XX y culmina en la década de 1950. La producción de vino se desplaza desde los cerros próximos al núcleo urbano hacia las zonas bajas del término, mejor comunicadas. Las bodegas rupestres, que fueron el centro neurálgico en la producción de vino, pierden su función original y, en muchas ocasiones, se dirigen hacia el camino del abandono y el derrumbe, pese a suponer un valioso patrimonio etnográfico. En el mejor de los casos se reconvierten en merenderos, verdaderos puntos de encuentro para familiares y amigos. No hay que olvidar que la bodega es un espacio, además de trabajo, de socialización en el que se comparten historias y vivencias en torno a un vaso de vino con vecinos y visitantes.

El segundo cambio se produce tras la constitución de la DOP (1980) y, especialmente, desde comienzos del siglo XXI. Se desarrolla un nuevo modelo de bodega que hace frente a las demandas actuales del mercado y a los cambios en el modelo de producción en un momento de fuerte competencia a nivel mundial del sector vitivinícola. Durante la industrialización temprana se incorporan nuevas técnicas constructivas y comenzaron a aparecer bodegas enfocadas a las economías de escala. A la consolidación de estas bodegas contribuyó el aumento de la elaboración de vino propiciado por la reforma de la reglamentación comunitaria. Se promovía la reconversión varietal con nuevas plantaciones de viñedos, con marcos de densidad que permitían un mayor número de cepas por hectárea y, por consiguiente, un incremento de la producción de uva.

Con ambos cambios, la dependencia de las laderas desaparece, pues se necesitan espacios llanos sobre los cuales se pueda edificar con facilidad y favorecer las labores que se desempeñan en las bodegas. El incremento del tamaño de las bodegas y el mayor volumen de vino producido pone de relieve la importancia de ubicarse en áreas accesibles, tanto a los viñedos como a los mercados, es decir, cerca de las carreteras. Ambas circunstancias concurren en la Ciudad de Borja en el área de la carretera que comunica la localidad con Soria y Zaragoza, por lo que la producción se desplaza a su entorno.

Tras la creación de las primeras bodegas industriales, los viticultores se organizan en cooperativas que tomaron el relevo a las primitivas bodegas industriales, y por su capacidad de aglutinar a los pequeños agricultores, terminan por precipitar el abandono de las bodegas emplazadas en el cerro. Este tipo de bodegas, en un contexto de migración del campo a la ciudad, tuvieron la capacidad de permitir el abastecimiento de los mercados urbanos y crear un modelo que perdura hasta la actualidad con la comercialización de grandes volúmenes de vino en mercados internacionales. 
Figura 11. Situación de las bodegas y cambios de ubicación de la producción del vino

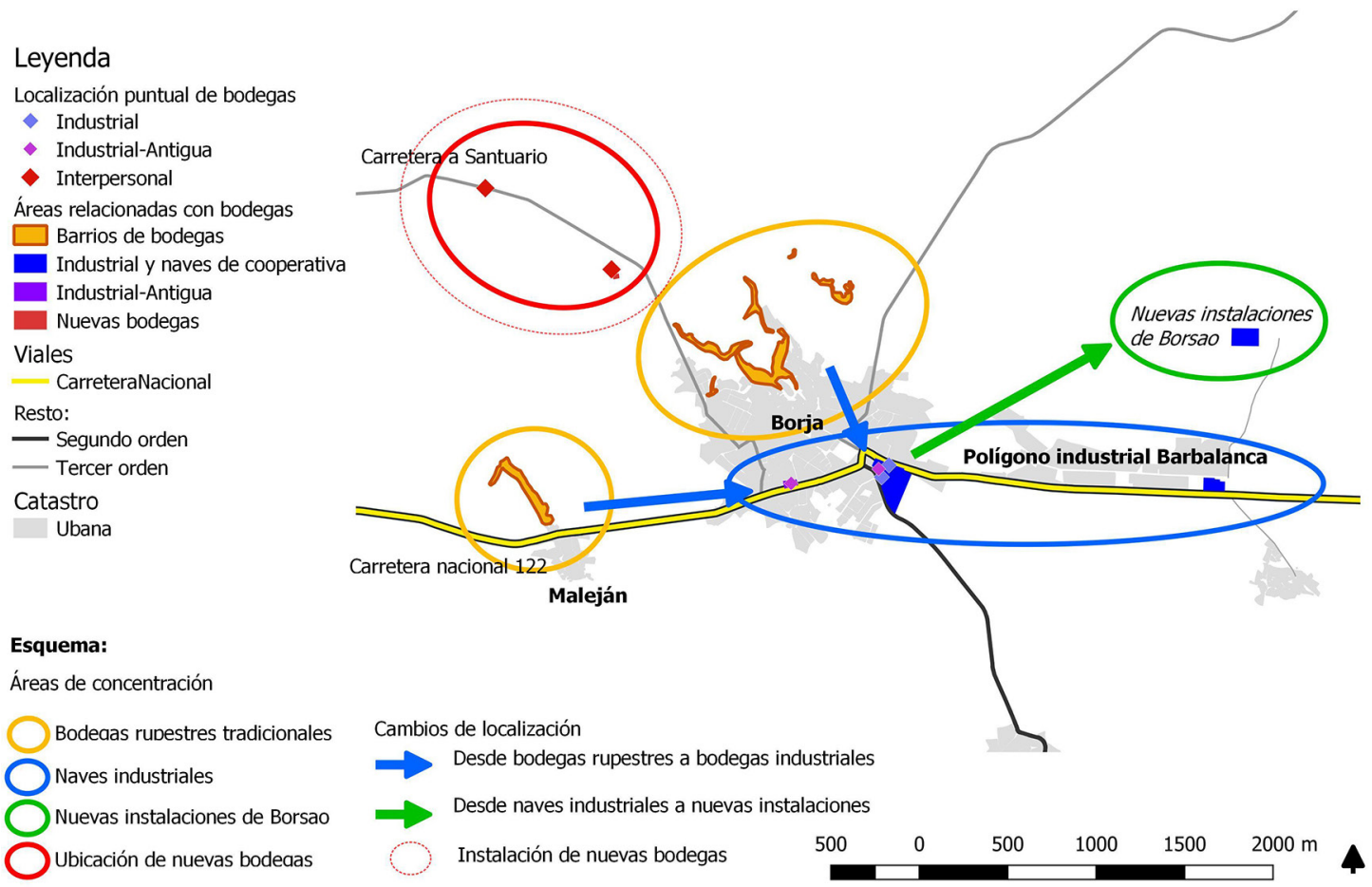

En la cartografía de bodegas industriales se han incluido las dependencias de la Cooperativa Agrícola de Borja en el polígono Barbalanca Fuente: cartografía de parcelas urbanas (Catastro). Elaboración propia

La creación de la DOP, y la apuesta por los productos de alta calidad que demanda el mercado en el contexto de la nueva cultura del vino, permiten la creación de bodegas pequeñas y muy especializadas en determinadas variedades como la garnacha. Además, este tipo de bodegas contribuye a mantener los viñedos viejos ante la política de arranque que ha tenido lugar en las últimas décadas, y que ha dado lugar a una perdida irrecuperable de estas plantas. La uva procedente de esta clase de viñedos es muy valorada para elaborar vinos de calidad, cualidad que este tipo de bodegas premia frente al volumen de vino.

Esta menor dependencia de una localización próxima a los ejes de comunicación principales les permite ubicarse en lugares de mayor riqueza paisajística. De nuevo, la parte alta del término municipal adquiere importancia, no obstante, no en las laderas, sino en espacios más amplios. Son lugares donde se pueden edificar nuevas bodegas que, en ocasiones, siguen las líneas de la enoarquitectura con diseños que poseen unos valores estéticos que van más allá de los requisitos funcionales que requiere la elaboración del vino. Además, esta ubicación y estos diseños se orientan hacia las tendencias que permiten un desarrollo potencial de nuevas actividades en el ámbito de los servicios como es la organización de catas, visitas guiadas o actividades de restauración.

\section{Discusión de resultados}

La industria vitivinícola es una actividad agroalimentaria que en las últimas décadas ha experimentado transformaciones muy significativas en todo su sistema, es decir, cambios a la hora de plantar viñedos, en el empleo de nuevos productos fitosanitarios en el campo, elaboración de vinos cada vez más diversos para un mercado en expansión territorial, así como cambios en la construcción y localización de las bodegas. Estas modificaciones han sido necesarias, pues la competencia en este sector es cada vez mayor, y las bodegas han tenido que reinventarse para hacerse más competitivas y destacar sobre otros centros de producción.

La localización de las bodegas es un factor que ha tenido y sigue teniendo un fuerte peso a la hora de elegir su emplazamiento. En un principio primaban, por un lado, los condicionantes del medio físico, pues se aprovechaban aquellos espacios con materiales más blandos que permitían excavar galerías subterráneas como por ejemplo en Borja (Chueca Yus, 2004) o en la comarca del Cerrato Palentino (Franco Jubete y 
Luis del Río, 2005). Por otro lado, su cercanía al núcleo urbano como sucede en los municipios de La Rioja (Palacios García, 2014) o en las localidades de la comarca vitivinícola de Cigales en la provincia de Valladolid (Fernández Portela, 2018), y que se debe a un ámbito de consumo personal y local, así como por las dificultades del transporte. Sin embargo, la lógica en el emplazamiento de las bodegas ha cambiado en las últimas décadas y la mayoría de ellas ha tenido en cuenta la cercanía a las vías de comunicación, autovías o carreteras nacionales y comarcales, requisitos que resultan ser indispensables para poder desarrollar una actividad económica que implica la llegada y salida de mercancías en grandes vehículos.

Por lo tanto, el emplazamiento es un criterio esencial que hay que tener en cuenta a la hora de establecer una bodega. Permite estar cerca de los consumidores y ahorrar costes en el transporte, tal y como también afirman Fernández Cuesta y Fernández Prieto (1999). Es una situación que han reflejado y dado importancia otros autores como Meza, Mascaray y Albisu (2001) para el caso de las industrias agroalimentarias de La Rioja, entre ellas las bodegas, y que además indican que la gran mayoría se localizan en áreas rurales, en las inmediaciones de carreteras. Esto refuerza la idea de su emplazamiento en espacios con buenas comunicaciones, pero al mismo tiempo con cierta calidad medioambiental.

Aparte de para la actividad vitivinícola, el emplazamiento juega un papel clave para el desarrollo de otras actividades económicas relacionadas con el mundo del vino, como, por ejemplo, el enoturismo. Es una actividad, principalmente de fin de semana, y que requiere buena conexión entre las ciudades y los centros receptores de turistas. Debe permitir salidas de un par de días sin perder mucho tiempo en los desplazamientos.

Algunas de las bodegas que conforman el área de estudio no desarrollan actividades de tipo turístico, a pesar de que existe la Ruta del Vino de la Garnacha que tiene en Borja su sede principal. Sin embargo, en el conjunto del territorio español, el interés por parte de la población hacia esta tipología turística aumenta año tras año según cifras de la Asociación Española de Ciudades del Vino (ACEVIN) con millones de personas ${ }^{17}$.

Debido al potencial con el que cuenta la ciudad de Borja en el campo vitivinícola y a la existencia de la Ruta del Vino de la Garnacha, apostar por el desarrollo del enoturismo podría permitir a este espacio diversificar su economía aprovechando la base de un producto tan característico y arraigado en el territorio como es el vino y su cultura. Los programas de visita a las instalaciones de las bodegas se podrían completar con otras actividades como pueden ser paseos por los viñedos, catas de vino, exposiciones y recorridos por las bodegas rupestres. Esto podría ser un aliciente para su conservación. A todo esto, hay que añadir el resto de atractivos turísticos de este espacio como es la gastronomía, el arte, los festejos populares, la naturaleza, etc., que pueden completar una oferta enoturística de calidad.

Estas iniciativas no son nuevas, y se han puesto en marcha en numerosas comarcas vitivinícolas en toda España con resultados satisfactorios. Ejemplo de ello son las investigaciones realizadas en espacios vitivinícolas como el de Jerez (López Sánchez, 2010), Alicante y Murcia (Martínez Puche y Morales Yago, 2016), Cigales (Fernández Portela, 2018), o en el Penedés (Molleví Bortoló y Miró Pérez, 2018), donde se resalta el papel trascendental que juega esta actividad en la diversificación económica y el desarrollo del medio rural, una idea que sería interesante poder aplicar a la ciudad de Borja y su entorno para ver si este impacto socio-económico (positivo) se repetiría también en este espacio vitivinícola aragonés.

La sociedad urbana vuelve los ojos hacia el medio rural. En ocasiones, esto se hace a través de visiones idealizadas del mismo (Paniagua Mazorra y Hoggart, 2002). En este contexto, paisajes agrarios como los del viñedo, que cuentan con una valoración paisajística positiva, se encuentran en un proceso de patrimonialización (Silva Pérez, 2009). El turismo rural ha sido "un acicate fundamental para la preservación, recuperación y revalorización del patrimonio natural y cultural" (Esparcia Pérez, Escribano Pizarro y Sánchez Aguilera, 2017, p. 416). La causa es que los valores locales han cobrado importancia, ganando peso los elementos singulares de estos espacios, es decir, lo genuino, lo "auténtico". En este marco, elementos como las fiestas y la cultura popular se han incorporado a las nuevas consideraciones de patrimonio.

Las bodegas rupestres del Campo de Borja, además de ser un signo distintivo de su paisaje, pueden jugar también un importante papel en este sentido. Entidades como la Asociación para la Promoción Turística de La Ruta de la Garnacha del Campo de Borja ha puesto en marcha iniciativas para integrar estas bodegas en la oferta turística de la zona con el fin de generar rentas territoriales en combinación con otros

17 https://www.wineroutesofspain.com/ 
elementos como el viñedo ${ }^{18}$. Una gestión adecuada de los elementos patrimoniales de las DOP puede ayudar generar rentas (Climent López y Esteban Rodríguez, 2018). Para ello, en el Campo de Borja se trabaja desde múltiples dimensiones; no solo desde la óptica del turismo, sino también desde la puesta en valor del vino. La zonificación de los diferentes terroir presentes en la DOP es una apuesta hacia la calidad del producto y la búsqueda de valor desde los propios viñedos (Lorente Blasco, 2017).

Finalmente, y una vez realizado el estudio, sería interesante plantear una nueva línea de trabajo que relacione la geografía del vino, el paisaje, el turismo y la sostenibilidad (Cañizares Ruiz y Ruiz Pulpón, 2020). La actividad vitivinícola que compone el entorno de la ciudad de Borja debe apostar de forma clara por la sostenibilidad como están haciendo otros espacios productores de vino. Ejemplo de ello es el trabajo de Binimelis Sebastián (2019) en Mallorca respecto al cultivo de la vid donde las nuevas plantaciones se han llevado a cabo con nuevos marcos de plantación y se han sustituido algunas técnicas químicas por otras mecánicas como por ejemplo la escarda. También cabe destacar el trabajo realizado por Triviño Tarradas (2019) en la DOP Montilla-Moriles con explotaciones vitivinícolas y bodegas cada vez más resilientes, donde el medio ambiente y la conservación del paisaje adquieren un papel esencial. El cambio en el emplazamiento de las bodegas conlleva la construcción de nuevos espacios para elaborar el vino, como se ha visto en el caso de la ciudad de Borja con las Bodegas Alto Moncayo y Morca.

En estas nuevas instalaciones sería recomendable que se implementaran políticas más sostenibles encaminadas a conseguir algunos de los Objetivos de Desarrollo Sostenible. La geografía y la sostenibilidad son dos conceptos que se encuentran íntimamente ligados. Por ello sería interesante que la geografía abordarse este tema de estudio ofreciendo su visión espacial y su capacidad para integrarla en conceptos como son la sostenibilidad económica, social y ambiental.

\section{Conclusiones}

En este análisis, se han explicado los factores que inciden en la localización de los tres tipos de bodegas delimitadas en el entorno de la ciudad de Borja y los efectos territoriales que han tenido sobre el paisaje y sobre el propio plano urbano. Se observan diferencias en las pautas de localización de los diferentes tipos de bodega, hasta el punto de ocupar espacios físicos diferentes dentro de la ciudad. Los diversos tipos de bodega han aparecido, secuencialmente, de la mano de cambios tecnológicos, de políticas y normativas vitivinícolas y por las convenciones dominantes en el sector.

Los resultados obtenidos confirman la hipótesis de partida. En el caso de Borja, cada tipo de bodega ocupa espacios diferenciados porque cada uno de ellos sigue unas pautas de localización propias y diferentes del resto. Las pautas de localización están determinadas por el potencial que cada ubicación ofrece a cada tipología de bodega y cómo, en cada lugar, las limitaciones de cada modelo pueden ser superadas con mayor facilidad. Las posibilidades que ofrece cada ubicación para la producción del vino dependen de la época y el modelo productivo propio de la bodega. Esto ha tenido un efecto sobre el territorio. Los cambios de paradigma dentro del sector han desembocado en la aparición de nuevos tipos de bodega, se han manifestado en el espacio urbano determinando cómo se distribuyen las bodegas en el área de estudio.

\section{Agradecimientos}

La realización de este trabajo no hubiera sido posible sin la colaboración de Antonio Serrano Sartaguda y Vicente Urchaga Andía, naturales de la ciudad de Borja.

\section{Referencias}

Amato, V. y Valleta, M. (2017). Wine landscape of Italy. En M. Soldati y M. Marchetti (Eds.), Landscapes and Landforms of Italy (pp. 523-536). https://doi.org/10.1007/978-3-319-26194-2_45

Alonso Santos, J.L. (2003). Redes y procesos de innovación en las comarcas vitivinícolas de Castilla y León: el ejemplo de la D.O. Bierzo. Boletín de la Asociación de Geógrafos Españoles, 36, 43-60. Recuperado de https://bage.age-geografia.es/ojs/index.php/bage/article/view/457

18 Campo de Borja busca recuperar las bodegas en cerro para mejorar su oferta turística. EUROPA PRESS - HERALDO DE ARAGÓN. Laura Uranga (3/7/2018). https://www.heraldo.es/noticias/aragon/zaragoza/2018/07/03/campo-borja-busca-recuperar-las-bodegascerro-para-mejorar-oferta-turistica-1253760-2261126.html 
Alonso Santos, J. L., Aparicio Amador, L. J. y Sánchez Hernández, J. L. (2003). Los espacios vitivinícolas en Castilla y León: la evolución hacia un sistema productivo de calidad. Boletín de la Asociación de Geógrafos Españoles, 35, 101-122. Recuperado de https://bage.age-geografia.es/ojs/index.php/bage/ $\underline{\text { article/view/445 }}$

Aparicio Amador, J., Sánchez Hernández, J.L., Alonso Santos, J.L. y Rodero González, V. (2008). La Ribera del Duero, geografía de un medio innovador en torno a la vitivinicultura. Scripta Nova, XII(277). Recuperado de http://www.ub.edu/geocrit/sn/sn-277.htm

Binimelis Sebastián, J. (2019). La transición post-productivista del sector vitivinícola de Mallorca (19902015). Boletín de la Asociación de Geógrafos Españoles, 80, 1-37. https://doi.org/10.21138/bage.2725

Buján, J. (2003). Guía de la Nueva Cultura del Vino. Barcelona: Rubes.

Camaioni, C. y D’Onofrio, R. (2016). Vineyard landscape in Italy: cases of territorial requalification and governance strategies. Landscape Research, 41(7), 714-729. https://doi.org/10.1080/01426397.2016. $\underline{1212323}$

Cañas Guerrero, I., Fuentes Pardo, J.M. y Martín Ocaña, S. (2006). Bodegas subterráneas tradicionales en la Ribera del Duero. En A. Alonso González y P. Rodríguez de las Heras (Coords.), Viticultura y enología en la DO Ribera del Duero (pp. 75-80). Burgos: Consejo Regulador de la DO Ribera del Duero.

Cañizares Ruiz, M.C. y Ruiz Pulpón, A.R. (2020). Paisajes del viñedo, turismo y sostenibilidad: interrelaciones teóricas y aplicadas. Investigaciones Geográficas, (74), 9-28. https://doi.org/10.14198/ INGEO2020.CRRP

Chueca Yus, V.M. (2004). Las bodegas rupestres del Campo de Borja. En I. Aguilera Aragón y M.F. Blasco Sancho (Coords.), Comarca del Campo de Borja (pp. 263-270). Zaragoza: Ed. Diputación General de Aragón.

Climent López, E. y Esteban Rodríguez, S. (2018). Paisaje y patrimonio territorial en las Denominaciones de Origen vinícolas del Valle del Ebro (España). E3S Web Conf. 50 01046. DOI: 10.1051/ e3sconf $/ 20185001046$

Escalona Orcao, A. I., Loscertales Palomar, B. y Climent López, E. (2013). Enfoques, experiencias y propuestas para la mejora de la competitividad territorial de las áreas vitivinícolas: Las denominaciones de origen protegidas de la provincia de Zaragoza. Boletín de la Asociación de Geógrafos Españoles, 62, 317-341. https://doi.org/10.21138/bage.1580

Esparcia Pérez, J., Escribano Pizarro, J., y Sánchez Aguilera, D. (2017). Los territorios rurales. En J. Romero (Coord.), Geografía Humana de España (pp. 367-448). Valencia: Tirant humanidades.

Esteban Rodríguez, S. (2017). Cambios en las Denominaciones de Origen Protegidas del sector del vino en España: Movimientos entre mundos de producción. Boletín de la Asociación de Geógrafos Españoles, 74, 483-513. https://doi.org/10.21138/bage.2463

Fernández Cuesta, G. y Fernández Prieto, J.R. (1999). Atlas industrial de España. Desequilibrios territoriales $y$ localización de la industria. Oviedo: Ediciones Nobel.

Fernández Portela, J. y García Velasco, M.A. (2014). Las bodegas tradicionales: patrimonio olvidado en la cultura del vino en la Denominación de Origen Cigales (Castilla y León, España). Geographicalia, 65, 61-86. https://doi.org/10.26754/ojs_geoph/geoph.201465866

Fernández Portela, J. (2018). La diversificación económica en una comarca vitivinícola tradicional: las bases que sustentan el enoturismo en la denominación de origen Cigales (Valladolid). Espacio, Tiempo y Forma. Serie VI, Geografía, 11, 141-168. https://doi.org/10.5944/etfvi.11.2018.20868

Franco Jubete, F. y Luis del Río, S. (2005). Cultura vitivinícola del Cerrato castellano: viñedos, vinos y bodegas del Cerrato palentino. Palencia: Itagra.

González Hinojo, M.A. (1995). La viña y la bodega de Jerez: útiles de trabajo. Narria: Estudios de artes y costumbres populares, 69(70), 27-33.

Huetz de Lemps, A. (1967a). Vignobles et vins du nord-ouest de l'Espagne. Tome I. Bordeaux: Institut de Géographie.

Huetz de Lemps, A. (1967b). Vignobles et vins du nord-ouest de l'Espagne. Tome II. Bordeaux: Institut de Géographie. 
Jové Sandoval, F. (2018). Arquitectura del vino: las bodegas tradicionales como patrimonio cultural. Biblioteca, estudio e investigación, 33, 247-266.

López Ocón, E. (2015). Caracterización de los barrios de bodegas subterráneas de la denominación de origen calificada Rioja. Estudio y comparación de sus condiciones interiores con las de las nuevas bodegas comerciales (Tesis doctoral). Universidad Politécnica de Madrid. Recuperado de http://oa.upm. es/38381/

López Sánchez, J.A. (2010). Posibilidades de desarrollo del enoturismo en la denominación de origen Jerez-Xerry-Sherry y manzanilla de Sanlúcar de Barrameda y Vinagre de Jerez. Boletín de la Asociación de Geógrafos Españoles, 53, 21-41. Recuperado de https://bage.age-geografia.es/ojs/index.php/bage/ article/view/1191

Lorente Blasco, M. (2017). Zonificación de la DOP Campo de Borja con criterios de Terroir (Tesis doctoral). Universidad de Zaragoza. Recuperado de https://www.educacion.gob.es/teseo/mostrarSeleccion.do

Loscertales Palomar, B., Escalona Orcao, A.I. y Climent López, E. (2011). Cambios recientes en el sector vitivinícola: el caso de las denominaciones de origen zaragozanas, Geographicalia, 59, 227-240. https://doi.org/10.26754/ojs_geoph/geoph.201159-60834

Macedo, M. (2011). Port wine landscape: railroads, phylloxera, and agricultural science. Agricultural history, 85(2), 157-173. https://doi.org/10.3098/ah.2011.85.2.157

Martín Martín, M.G. (2016). Las bodegas tradicionales: Localización, construcción y uso. En J. Fernández Portela (Coord.), La comarca vitivinícola de Cigales: viñedos, bodegas y vinos. 25 años de la D.O. Cigales (pp. 117-137). Valladolid: Consejo Regulador de la D.O. Cigales.

Martínez-Carrasco, L., Brugarolas, M. y Martínez-Poveda, A. (2005). Quality wines and wines protected by a designation of origin: identifying their consumption determinants. Journal of wine research, 16(3), 213-232. https://doi.org/10.1080/09571260600556690

Martínez Puche, A. y Morales Yago, FJ. (2016). El vino como recurso turístico para el fomento del desarrollo local: una oportunidad para las comarcas del Vinalopó (Alicante) y el Altiplano YeclaJumilla (Murcia). Cuadernos de Turismo, 38, 267-300. https://doi.org/10.6018/turismo.38.271451

Meza, L. Mascaray, M.A. y Albisu Aguado, L.M. (2001). La localización de la industria agroalimentaria en La Rioja: núcleos rurales versus núcleos urbano. Berceo, 141, 229-246.

Miranda Escolar, B. y Fernández Morueco, R. (2011). Vino, turismo e innovación: las Rutas del Vino de España, una estrategia integrada de desarrollo rural. Estudios de Economía Aplicada, 29(1), 129-164. Recuperado de https://www.redalyc.org/articulo.oa?id=30120835005

Molleví Bortoló, G. y Miró Pérez, A.P. (2018). La denominación de origen Penedés: contexto histórico, geográfico y enoturístico. Geographicalia, 70, 27-53. https://doi.org/10.26754/ojs_geoph/ geoph.2018703279

Palacios García, M. (2014). Los barrios de bodegas tradicionales de La Rioja. Berceo, 167, 61-87.

Paniagua Mazorra, A. y Hoggart, K. (2002). Lo rural ihechos, discursos o representaciones? Una perspectiva geográfica de un debate clásico. Información Comercial Española, 803, 61-72.

Pastor, G., Torres, L. y Marinsalda Pastor, L. (2020). Landscape enclaves: wine capitalism and luxury tourism in Mendoza, Argentina. Journal of Political Ecology, 27(1), 580-593. https://doi.org/10.2458/ $\underline{\mathrm{v} 27 \mathrm{i} 1.22953}$

Plaza Tabasco, J., Cañizares Ruiz, M.C. y Ruiz Pulpón, A. (2017). Patrimonio, viñedo y turismo: recursos específicos para la innovación y el desarrollo territorial de Castilla La Mancha. Cuadernos de Turismo, 40, 547-571. http://dx.doi.org/10.6018/turismo.40.310101

Rocchi, B. y Gabbai, M. (2013). Territorial identity as a competitive advantage in wine marketing: a case study. Journal of wine research, 24(4), 291-310. https://doi.org/10.1080/09571264.2013.837382

Ruiz Budría, E., Castelló Puig, A., Climent López, E., Escalona Orcao, A.I., Hernández Navarro, M.L., Loscertales Palomar, B. y Frutos Mejías, L.M. (2013). La calidad del vino a la luz de la teoría de las convenciones: aplicación a las denominaciones de origen aragonesas. Estudios geográficos, 74(274), 231-254. https://doi.org/10.3989/estgeogr.201308

Salais, R. y Storper, M. (1992). The four 'Worlds' of Contemporary Industry. Cambridge Journal of Economics, 16, 169-193. https://doi.org/10.1093/oxfordjournals.cje.a035199 
Sánchez Hernández, J. L. (2003). Capital exógeno y procesos de innovación en la industria vinícola de la Denominación de Origen Toro. Boletín de la Asociación de Geógrafos Españoles, 36, 61-79. Recuperado de https://bage.age-geografia.es/ojs/index.php/bage/article/view/458

Sánchez Hernández, J., Aparicio Amador, J., y Alonso Santos, J. (2010). The Shift between Worlds of Production as an Innovative Process in the Wine Industry in Castile and Leon, Spain. Geoforum, 41(3), 469-478. https://doi.org/10.1016/j.geoforum.2009.12.004

Silva Pérez, R. (2009). Agricultura, paisaje y patrimonio territorial. Los paisajes de la agricultura vistos como patrimonio. Boletín de la Asociación de Geógrafos Españoles, 49, 309-334. https://bage.agegeografia.es/ojs/index.php/bage/article/view/786

Steakley, J. y Steakley B. (2020). A Quest for Quality Wine, Every Time. Cham: Springer. https://doi. org/10.1007/978-3-030-34000-1

Triviño Tarradas, P.M. (2019). Evaluación y mejoras para el manejo sostenible de la explotación vitivinícola en la DOP Montilla-Moriles (Tesis Doctoral). Universidad de Córdoba. Recuperado de https://helvia. uco.es/xmlui/handle/10396/18428 